Elsevier Editorial system(tm) for

Spectrochimica Acta Part A: Molecular and Biomolecular spectroscopy Manuscript Draft

Manuscript Number:

Title: Reflection FTIR spectroscopy for the study of historical bowed string instruments: invasive and non-invasive approaches

Article Type: Full Length Article

Section/Category: Analytical Spectroscopy and New Methods

Keywords: Wooden historical artefacts; Reflection FTIR Spectroscopy; Chemical mapping.

Corresponding Author: Dr. Monica Gulmini,

Corresponding Author's Institution: Università degli Studi di Torino

First Author: Fiocco Giacomo

Order of Authors: Fiocco Giacomo; Claudia Invernizzi; Silvia Grassi; Patrizia Davit; Michela Albano; Tommaso Rovetta; Chiaramaria Stani; Lisa Vaccari; Marco Malagodi; Maurizio Licchelli; Monica Gulmini

Abstract: A micro-sample detached from a historical bowed string instrument represents a valuable record that allows researchers to collect a wealth of information concerning the materials used by the great Masters of violin-making art and to disclose - at least partially their procedures for finishing and varnishing.

In the present work, a set of four cross-sectioned micro-samples collected from well-preserved bowed string instruments made by Antonio Stradivari and Lorenzo Storioni - are investigated by Synchrotron Radiation (SR) FTIR micro-spectroscopy in reflection mode. SR-FTIR spectra are considered both as point analysis and as univariate and multivariate chemical maps. Moreover, data obtained by a non-invasive approach with a portable reflection FTIR spectrometer and SEM-EDX data on the same cross-sections are also considered.

FTIR investigation of the cross-sections is a challenging task for such brittle and complex layered micro-samples. Nevertheless, the high

intensity of the analytical SR beam used in reflection geometry allowed us to obtain informative FTIR spectra and to fully preserve the integrity of the samples.

Both the non-invasive and the micro-invasive reflection FTIR approaches can reveal the materials spread on the wood surface to finish the musical instruments. The fingerprint of Lorenzo storioni in his production around 1790 is highlighted in the cross sectioned samples, definitely different from the technique of Stradivari.

Suggested Reviewers: Austin Nevin University of Goteborg - Department of Conservation austin.nevin@gu.se He has a long standing experience in the study of ancient and modern cultural heritage using optical and spectroscopic techniques. 
Silvia Prati

University of Bologna

s.prati@unibo.it

She is an expert in the characterization of organic and inorganic components in manufacts of historical, artistic and archaeological interest, with a focus on FTIR techniques.

Francis W.M.R. Schwarze

Swiss Federal Laboratories for Materials Science and Technology - EMPA francis.schwarzedempa.ch

He contributed significantly to wood science and technology and to the investigation of multi-layered treatments for the enhancement of acoustic properties of violins. 


\section{Università degli Studi di Torino}

Dipartimento di Chimica

Via P. Giuria, 710125 Torino Italy

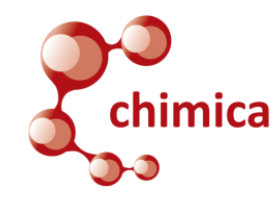

Dott.ssa PhD Monica Gulmini

phone: +39 0116705265

e-mail:monica.gulmini@unito.it

Gruppo: Archeometria e Metodi Analitici

per Materiali Artistici, Storici e Archeologici - AMAMASA -

\author{
Spectrochimica Acta Part A \\ Molecular and Biomolecular \\ Spectroscopy
}

Torino, $06^{\text {th }}$ Aprile, 2020

Dear Editor,

on behalf of all the co-authors, I am submitting the manuscript entitled:

"Reflection FTIR spectroscopy for the study of historical bowed string instruments: invasive and non-invasive approaches"

to be considered for publication in Spectrochimica Acta part A - Molecular and Biomolecular Spectroscopy.

The manuscript reports the investigation by FTIR spectroscopy in reflection mode of wellpreserved bowed string instruments made by Antonio Stradivari and Lorenzo Storioni, and of some micro-samples detached from them.

The non-invasive approach by a portable FTIR apparatus is discussed along with the data obtained by Synchrotron Radiation FTIR on samples mounted in cross section. SR-FTIR is a well-established technique for investigating cross-sections from paintings, the manuscript focuses on issues and perspectives of the approach that are relevant for the investigation of historic musical instruments, as this topic has not been considered yet throughout.

Univariate and multivariate imaging techniques are employed in our work to provide a visual representation of the SR-FTIR results obtained on cross sectioned samples.

Besides elucidating differences and similarities in the materials and methods used by the two Masters, the analytical procedures employed to recover the overall information from the samples - and to display it effectively - are discussed. The authors believe that the topic will be of interest for researchers involved in the investigation of challenging micro-samples and precious historical artefacts.

The work was entirely performed by the team of the co-authors; it has not been published previously nor it is under consideration for publication elsewhere.

The submission is approved by all authors and by the responsible authorities where the work has been carried out.

Yours sincerely,

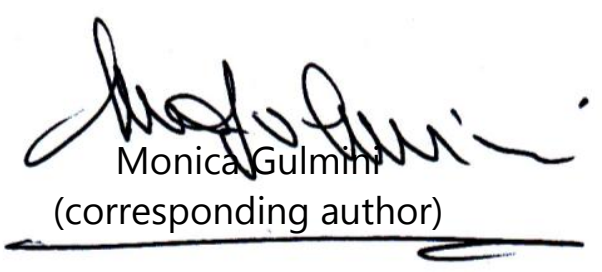




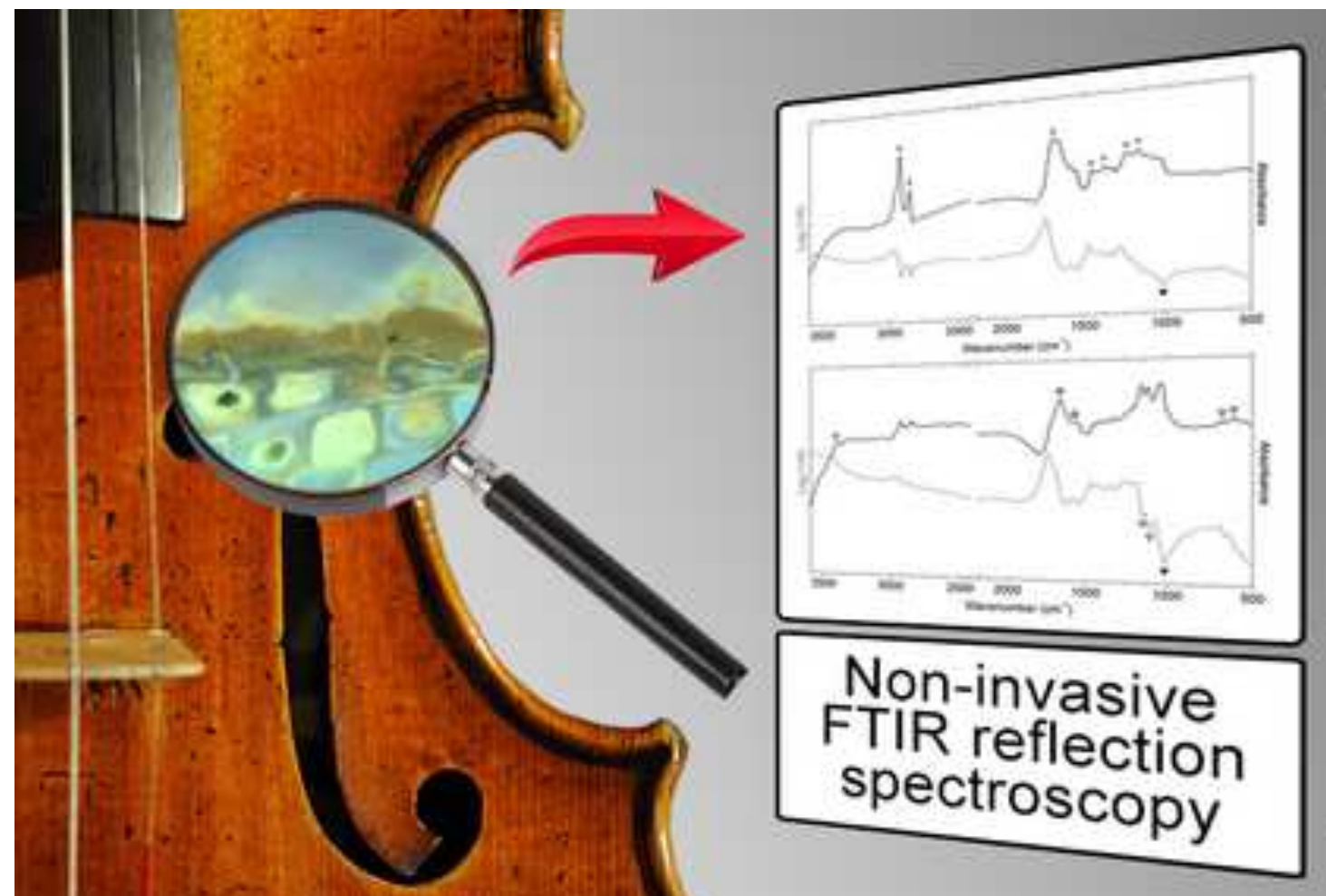

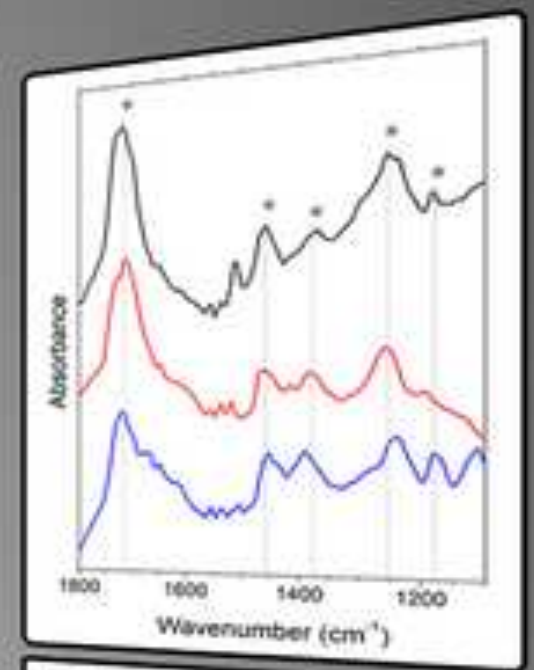

Micro-invasive SR-FTIR spectroscopy

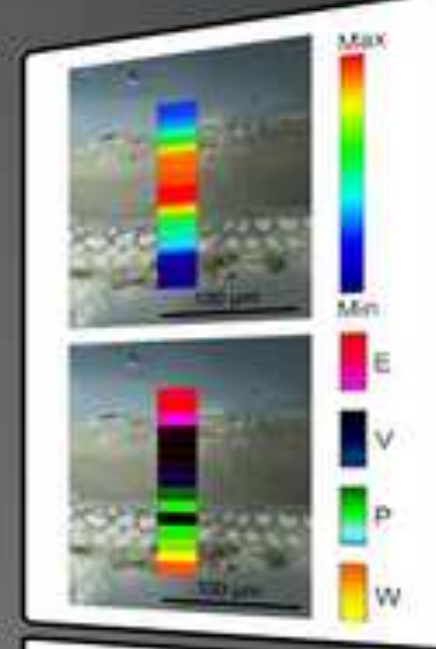

Chemical imaging 
Highlights (for review)

\section{Highlights}

SR beam in the micro-FTIR equipment preserved the superficial integrity of the sample.

The fingerprint of Storioni's production around 1790 was highlighted.

Both invasive and non-invasive approaches yielded information on the stratigraphy.

Multivariate mapping was effective in imaging the multi-layered coating system. 


\title{
Reflection FTIR spectroscopy for the study of historical bowed string instruments: invasive and non-invasive approaches
}

\author{
Giacomo Fiocco, ${ }^{1,2}$ Claudia Invernizzi, ${ }^{1,3}$ Silvia Grassi, ${ }^{4}$ Patrizia Davit, ${ }^{2}$ Michela Albano, ${ }^{1,5}$ \\ Tommaso Rovetta, ${ }^{1}$ Chiaramaria Stani, ${ }^{6}$ Lisa Vaccari, ${ }^{6}$ Marco Malagodi, ${ }^{1,7}$ Maurizio Licchelli, ${ }^{1}$ \\ and Monica Gulmini *,2 \\ ${ }^{1}$ Laboratorio Arvedi di Diagnostica Non Invasiva, CISRiC, Università degli Studi di Pavia, Via Bell'Aspa 3, 26100 \\ Cremona, Italy; giacomo.fiocco@unipv.it, claudia.invernizzi@unipv.it, michela.albano@unipv.it, \\ tommaso.rovetta@unipv.it,marco.malagodi@unipv.it, maurizio.licchelli@unipv.it \\ 2 Dipartimento di Chimica, Università di Torino, Via Pietro Giuria 7, 10125, Torino, Italy; patrizia.davit@unito.it, \\ monica.gulmini@unito.it \\ ${ }^{3}$ Dipartimento di Scienze Matematiche, Fisiche e Informatiche, Università degli Studi di Parma, Parco Area delle \\ Scienze, 7/A, 43124 Parma, Italy \\ ${ }^{4}$ Dipartimento di Scienze per gli Alimenti, la Nutrizione e l'Ambiente, Università degli Studi di Milano, Via Celoria, \\ 2, 20133, Milano, Italy; silvia.grassi@unimi.it \\ ${ }^{5}$ Dipartimento di Fisica, Politecnico di Milano, Piazza Leonardo da Vinci 32, 20133, Milano, Italy. \\ ${ }^{6}$ Elettra-Sincrotrone Trieste S.C.p.A., S.S. 14 km 163.5, 34194 Basovizza, Trieste, Italy; \\ chiaramaria.stani@elettra.eu, lisa.vaccari@elettra.eu \\ ${ }^{7}$ Dipartimento di Musicologia e Beni Culturali, Università degli Studi di Pavia, Corso Garibaldi 178, 26100 \\ Cremona, Italy \\ * Corresponding author: monica.gulmini@unito.it
}

\begin{abstract}
A micro-sample detached from a historical bowed string instrument represents a valuable record that allows researchers to collect a wealth of information concerning the materials used by the great Masters of violin-making art and to disclose - at least partially - their procedures for finishing and varnishing.

In the present work, a set of four cross-sectioned micro-samples - collected from well-preserved bowed string instruments made by Antonio Stradivari and Lorenzo Storioni - are investigated by Synchrotron Radiation (SR) FTIR micro-spectroscopy in reflection mode. SR-FTIR spectra are considered both as point analysis and as univariate and multivariate chemical maps. Moreover, data obtained by a noninvasive approach with a portable reflection FTIR spectrometer and SEM-EDX data on the same crosssections are also considered.

FTIR investigation of the cross-sections is a challenging task for such brittle and complex layered micro-samples. Nevertheless, the high intensity of the analytical SR beam used in reflection geometry allowed us to obtain informative FTIR spectra and to fully preserve the integrity of the samples.

Both the non-invasive and the micro-invasive reflection FTIR approaches can reveal the materials spread on the wood surface to finish the musical instruments. The fingerprint of Lorenzo Storioni in his production around 1790 is highlighted in the cross sectioned samples, definitely different from the technique of Stradivari.
\end{abstract}

\section{Keywords}

Wooden historical artefacts; Reflection FTIR Spectroscopy; Chemical mapping.

\section{Introduction}

The most charming and discussed part of a bowed stringed musical instrument is the varnish, remarkable result of the finishing treatments performed by ancient violin makers. Its role is not merely 
aesthetic and protective, since it influences - together with the ground coat - the mechanical and vibrational properties of the wooden parts and, consequently, the sound quality [1-4].

During the last decades, a suite of analytical techniques has been employed to investigate materials and procedures used for finishing historical string instruments [5,6], with a particular attention to those produced in Cremona (Italy) by the Amati, Guarneri, and Stradivari families [7-10]. As a general result, complex multi-layered systems - which were created on the wood through a wide variety of organic and inorganic materials - [11-15] have been highlighted.

Researchers are presently engaged in developing analytical procedures aimed at maximizing the information that can be retrieved from priceless historical musical instruments, in order to disclose how the finishing treatments were made [16] and if they are preserved over time. Due to their high value, sampling is seldom granted by conservators and owners of the instruments, therefore analyses on violins are often carried out through non-invasive approaches in order to fully preserve the integrity of the object [17-20]. Nevertheless, non-invasive approaches do not normally lead to both exhaustive and highly spatial-resolved chemical information [21,22], which is somehow more accessible if samples are available. These can be scrutinized with both elemental and molecular techniques [24-26] aimed at obtaining a thorough chemical characterisation of the materials composing the layers.

Under this scenario, infrared (IR) spectroscopies are perfect candidates as IR radiation enables the identification of both organic and inorganic chemical species. Portable FTIR reflection spectroscopy has been used to collect chemical information on artworks [26], even though a tentative non-invasive stratigraphic approach that considers spectra obtained by analysing differently preserved varnish areas of the bowed string musical instruments [27]. On the other hand, FTIR micro-spectroscopies can be exploited for investigating samples prepared as cross-sections [28,29]. Procedures specifically tailored for preparing cross-sectioned samples for FTIR investigations, avoiding the use of embedding resins which may interfere with the analytical steps, have been reported in the literature [30-32]. Nevertheless, samples detached from historical violins are extremely brittle and their inclusion into epoxy resin still appears the most feasible procedure to succeed in the preparation of cross-sections, ensuring that the stratigraphy can be preserved for further and more informative analysis that may be developed in the future.

In this work, reflection FTIR techniques have been employed for the analysis of three well-preserved bowed string instruments (Table 1) produced by two ancient Cremonese masters of the violin-making art, namely Antonio Stradivari (ca. 1644 - 1737) and Lorenzo Storioni (1744 - 1816) [33].

Table 1. List of violin makers, violins and related cross-sectioned samples.

\begin{tabular}{cccccc}
\hline Violin maker & $\begin{array}{c}\text { Instrument } \\
\text { name }\end{array}$ & $\begin{array}{c}\text { Year of } \\
\text { construction }\end{array}$ & Type & Part & Sample code \\
\hline & - & 1790 & Violin & Backplate & LS_1790 \\
\cline { 2 - 6 } L. Storioni $(1744-1816)$ & Bracco & 1793 & Small violin & Backplate & LS_1793a \\
\cline { 2 - 6 } & & & & Frontplate & LS_1793b \\
\hline A. Stradivari $(1644-1737)$ & Toscano & 1690 & Violin & Frontplate & AS_1690 \\
\hline
\end{tabular}

Synchrotron Radiation (SR) FTIR spectroscopy in reflection geometry was used to analyse the crosssectioned samples (Figure 1). SR can dramatically increase the lateral resolution and signal-to-noise ratio [34], making this technique particularly appropriate for the investigation of complex layered microstructures [35-39]. The reflection geometry avoids the contact between the probe and the sample, contrary to the FTIR-ATR setup condition [29], in which the tip seriously alters the morphology of the analytical spots and can therefore be considered as micro-destructive for these very brittle samples.

Spectroscopic data obtained on cross-sections are discussed in this work as both spot analysis and maps. As for maps, they normally show the intensities of the characteristic absorption bands according to a colour scale, thus depicting the spectral information and its spatial distribution on the sample area. 
In recent years, multivariate methods have been introduced for treating spectroscopic data [40]. In particular, they have been employed to support the interpretation of the data obtained from crosssectioned samples taken from paintings, in order to overcome some drawbacks of the chemical mapping and to enable a straightforward representation of the whole information occurring in the FTIR spectra [41-43]. Actually, Principal Component Analysis (PCA) enables the exploration of multivariate data - such as the spectral ones - through simple and effective graphical outputs which visualise the relationships between spectra in a scatter scores plot defined by representing the directions of maximum variation of the original data and the loads of the original variables in a loadings plot [44]. PC scores can be exploited to obtain pictures quite similar to chemical maps, but with a multivariate meaning. In that sense, false colour images are constructed with a chromatic scale based on scores for a single PC, or by the combination of the scores for more than one of them. Therefore, univariate and multivariate data analysis have been applied here in order to check the merits of visual images of components distribution for the investigated cross-sections.

SR-FTIR data on cross-sections are compared with the results obtained through the non-invasive investigation of the musical instrument with portable reflection FTIR. Optical microscopy under UV-light and SEM-EDX data are also considered to extend the overall information.
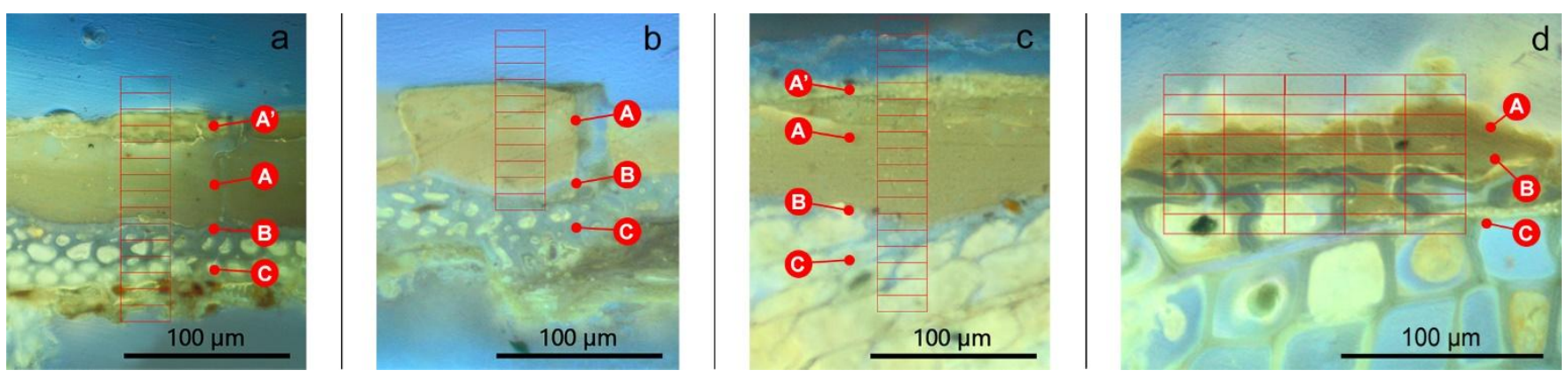

Figure 1. UV images of the four cross-sectioned samples: LS_1790 (a), LS_1793a (b), LS_1793b (c), and AS_1690 (d). The layers identified under the OM and described in 3.1 are indicated by capital letters. The red grid highlights the area considered for mapping (see 3.1 for details).

\section{Experimental}

The backplates of the Stradivari Toscano 1690 and the Storioni Bracco 1793 were first investigated by non-invasive FTIR analysis using an Alpha portable spectrometer (Bruker Optics, Germany/USA- MA) equipped with an R-Alpha external reflectance module (optical layout $23^{\circ} / 23^{\circ}$ ). The compact optical bench consists of a Globar, a permanently aligned RockSolid interferometer (with gold mirrors) and an uncooled DLaTGS detector. It was employed on the musical instruments at a working distance of 15 $\mathrm{mm}$, thus analysing spots of about $5 \mathrm{~mm}$ in diameter. Pseudo-absorbance spectra $[\log (1 / \mathrm{R}) ; \mathrm{R}=$ reflectance] were shown between 3600 and $500 \mathrm{~cm}^{-1}$, with a spatial resolution of $4 \mathrm{~cm}^{-1}$. Spectra from a gold flat mirror were used as background. Reflection infrared spectra were then transformed into absorbance spectra by applying the Kramers-Kronig Transformation (KKT) (included in the OPUS 7.2 software package). Analytical spots were selected on the basis of preliminary imaging of the musical instrument under visible and UV light $[45,46]$, in order to investigate variously preserved areas and retrieve information both from the varnish and from the underlying layers.

Sub-millimetric samples were detached by a scalpel from the most preserved area among those previously selected as non-invasive FTIR analytical spots. Samples were then embedded into epoxy resin (Epofix Struers and Epofix Hardener 15:2, w:w) and cut as cross-sections. Subsequently, the surface was dry-polished with silicon carbide fine sandpaper (500-8000 mesh).

The cross-sectioned polished samples were observed through an Olympus BX51TF polarized light optical microscope (OM) equipped with Olympus TH4-200 (visible light) and Olympus U-RFL-T (UV light) lamps. 
Imaging at higher magnifications was performed by a FE-SEM Tescan Mira 3XMU-series (Brno, Czech Republic) Scanning Electron Microscope (SEM) in back-scattered electron (BSE) mode, setting the accelerating voltage to $20 \mathrm{kV}$ in low vacuum (100 Pa nitrogen pressure) Elemental microanalysis was carried out using a Bruker Quantax 200 (Billerica, MA, USA) Energy-Dispersive X-ray spectrometer (EDX) coupled to the FE-SEM apparatus.

SR-FTIR analysis was carried out by the SISSI beamline (Chemical and Life Sciences branch) at Elettra Sincrotrone Trieste (Italy) [47]. Measurements were performed in reflection geometry using the Bruker Vertex 70v interferometer coupled with the Hyperion 3000 microscope (Bruker Optik GmbH) and a single point mercury-cadmium-telluride (MCT) detector. 512 scans were averaged, at $120 \mathrm{KHz}$ scanner speed, with a spectral resolution of $4 \mathrm{~cm}^{-1}$ in the spectral range $4000-750 \mathrm{~cm}^{-1}$. Spectra were pre-processed with a smoothing treatment (Savitzky-Golay method, 15 wavelengths gap size and $2^{\text {nd }}$ polynomial order). The knife-edge slits of the Vis-IR microscope were set to an acquisition area of $10 \mathrm{x}$ $30 \mu \mathrm{m}(10 \mu \mathrm{m}$ corresponds to the minimum thickness of the layers observed under the optical microscope). A gold substrate was employed for the background. Some spectra were collected by adjusting the lateral resolution in order to focus the analysis on one selected detail. In addition, "onecolumn" maps were collected from LS_1790 (15 rows), LS_1793a (11 rows), LS_1793b (18 rows), and a grid with 8 rows and 5 columns (40 spectra) was obtained from AS_1690. Univariate chemical maps were obtained by Opus 7.5 software package considering the characteristic signals for the varnish (the peak at $1710 \mathrm{~cm}^{-1}$ from ester and carboxylic acid groups of oils and resins), for proteins (the peak from $\mathrm{vC}=\mathrm{O}$, amide $\mathrm{I}$, at $1650 \mathrm{~cm}^{-1}$ ) and for the embedding agent (the peak at $1510 \mathrm{~cm}^{-1}$ from vC-C aromatic ring). The chromatic scale was set to range from red (highest values) to blue (lowest values). An interpolation algorithm was employed automatically by the software OPUS 7.5.

The multivariate approach considered a data matrix composed by as many rows as the total number of SR-FTIR spectra (84) and as many columns as the number of spectral variables (2606). Different spectral pre-treatments were combined with the Kramers-Kronig (KK) algorithm, namely smoothing (Savitzky-Golay, 11 wavelengths gap size), first derivative (Savitzky-Golay, 11 wavelengths gap size and $2^{\text {nd }}$ polynomial order) and mean centre. Exploratory data analysis was carried out by PCA, based on the singular value decomposition (SVD) algorithm [48]. The optimal number of Principal Components (PCs) to be retained was selected by evaluating the scree plot [49]. An interval-PCA approach was followed, i.e. different models were investigated in order to select the spectral ranges retaining the most relevant information [50]. The intervals investigated were $3500-3000 \mathrm{~cm}^{-1}, 3000-2700$ $\mathrm{cm}^{-1}, 2700-2300 \mathrm{~cm}^{-1}, 2100-1800 \mathrm{~cm}^{-1}, 1800-1550 \mathrm{~cm}^{-1}, 1550-1450 \mathrm{~cm}^{-1}, 1460-1260 \mathrm{~cm}^{-1}$, and $1250-$ $1000 \mathrm{~cm}^{-1}$. From the preliminary data exploration, it was noticed that relevant information was retained by merging the range $2000-1400 \mathrm{~cm}^{-1}$, being responsible for sample grouping according to the materials involved in the composition of the finishing layers, thus this region was used for further multivariate investigation. Score values from PCA were employed to obtain scores maps highlighting similarities (or differences) among the layers according to a multivariate approach. The scores maps resulted from a $3 D$ reconstruction similarly to $R G B$ images, where each channel - instead of merely representing the intensity of colour - is associated to the score value on PC1, PC2, and PC3 calculated for each grid point. Thus, the colour bars in the scores map have a multivariate meaning, as they represent the variance of the considered spectral range $\left(2000-1400 \mathrm{~cm}^{-1}\right)$, which can be related to "classes" of materials according to the indication given by the loadings plot. In multivariate maps, no smoothing was employed.

Data analysis was performed under Matlab environment (ver. 9.2, The Mathworks, Inc., Natick, USA) using the PLS toolbox (ver. 8.5, Eigenvector Research, Inc., USA) software package.

\section{Results and Discussion}

3.1 Morphological features, molecular and elemental data 
As expected, marker bands related to the embedding epoxy resin are evident in the SR spectra (Figure $\mathrm{SM1})$, but nevertheless these signals - appearing at $1610 \mathrm{~cm}^{-1}(\mathrm{~N}-\mathrm{H}$ deformation, primary amine; $\mathrm{vC}=\mathrm{C}$, aromatic ring), $1510 \mathrm{~cm}^{-1}$ (vC-C, aromatic ring), $1250 \mathrm{~cm}^{-1}$ (epoxy groups; vC-O), and $1035 \mathrm{~cm}^{-1}$ (vC-O$C$, ethers) [51-53] - can be easily singled out. Their intensity gradually decreases and disappears in the spectra recorded from the external layers to the wood substrate. Furthermore, as the interfaces are not clearly defined and layers are extremely thin, signals from various components are sometimes combined in the resulting spectra.

By observing the cross-sections of the two violins by Lorenzo Storioni under the OM with UV light (Figure 1, a-c), a common structure is evident for the coating systems. Samples LS_1790, LS_1793a and LS_1793b, in fact, show a thick varnish layer A $(60-90 \mu \mathrm{m})$ characterized by a homogeneous lightyellow UV fluorescence. Under the varnish, a thin preparation layer B (less than $10 \mu \mathrm{m}$ ) with light-blue fluorescence is spread directly on the wood $(C)$. In addition, a further external varnish layer A' (Figure 1, a,c) appears in LS_1790 and LS_1793b. SR-FTIR KKT spectra of layer A highlight the marker bands of a varnish made of a siccative oil and natural terpenic resins [7,19]: 1) sharp and intense $\mathrm{VCH}_{2}$ bands at $2920 \mathrm{~cm}^{-1}$ (asymmetric mode) and $2850 \mathrm{~cm}^{-1}$ (symmetric mode), characteristics of the oil with minor contribution from the resin; 2) weak $\mathrm{VCH}_{3}$ bands from the resin at $2950 \mathrm{~cm}^{-1}$ (asymmetric mode) and $2870 \mathrm{~cm}^{-1}$ (symmetric mode) (Figure 2, a); 3) intense $\mathrm{V}=\mathrm{O}$ at around $1710 \mathrm{~cm}^{-1}$ ascribable to the ester (oil) and carboxylic acid (resin) groups; 4) $\delta \mathrm{sCH}_{2}$ (oil and resin) and $\delta a s \mathrm{CH}_{3}$ (resin) at $1450 \mathrm{~cm}^{-1} ; 5$ ) $\delta \mathrm{sCH}_{3}$ (resin) at $1375 \mathrm{~cm}^{-1}$; 6) $\mathrm{V}$-O (oil) at 1255 and $1185 \mathrm{~cm}^{-1}$ (Figure 2, a,b). Bands related to a proteinaceous material - such as animal glue or casein - at $1650 \mathrm{~cm}^{-1}\left(\mathrm{VC}=\mathrm{O}\right.$, amide I) and $1550 \mathrm{~cm}^{-1}$ (combination of $v \mathrm{C}-\mathrm{N}$ and $\delta \mathrm{N}-\mathrm{H}$, amide II) [54,55] characterize all the KKT spectra collected on layer B (Figure 2, c). These results turned out to be in accordance with the non-invasive FTIR investigation performed on the backplate of the Bracco 1793 small violin [56] (Figure 3, a,b). In addition, some inorganic phases are mainly detected by the non-invasive analysis on the most worn-out areas of the Bracco: the Reststrahlen bands at around $1100-1000 \mathrm{~cm}^{-1}\left(\mathrm{~V}_{\mathrm{as}} \mathrm{Si}-\mathrm{O}-\mathrm{Si}\right)$ as well as the signals at 1150 and $1100 \mathrm{~cm}^{-1}\left(\mathrm{~V}_{\mathrm{as}} \mathrm{SO}_{4}\right)$, together with those at 670 and $600 \mathrm{~cm}^{-1}\left(\delta_{\mathrm{as}} \mathrm{SO}_{4}\right)$, can be attributed, respectively, to the silicate and sulphate groups $[57,58]$. The IR results are supported by EDX analyses performed on some particles found at the A-to-B interface and in the layer B itself, with the signals of $\mathrm{Si}$, $\mathrm{S}$ and $\mathrm{Ca}$ confirming the presence of silicates and calcium sulphates (probably gypsum). All these materials could be related to fillers dispersed in the organic binders $[59,60]$. In addition, EDX detects Fe in some red particles, leading us to hypothesize the use of iron-based red pigments $[61,62]$.

The microscopic observation under UV light of the sample AS_1690, obtained from the Toscano violin (Figure 1, d), shows two thin layers of about 10-15 $\mu \mathrm{m}$ each with a yellow and a whitish fluorescence, respectively layer $A$ and $B$.

Despite the low intensity of the signals, the KKT spectra collected from the two layers highlight the presence of an oil-terpenic resin varnish (Figure 2, a,b) in both layers. On the other hand, the spectra acquired at the interface between the spruce wood (layer $\mathrm{C}$ ) and layer $\mathrm{B}$ do not clearly point out the presence of a ground coat, since the characteristic signals for proteinaceous materials are not detected (Figure 2, c). A broad band, centered around $1650 \mathrm{~cm}^{-1}$, is instead detected on the backplate of the violin by the non-invasive analysis (Figure 3, c,d). This signal could be possibly attributed to proteinaceous materials, as already reported in [27].

SEM-EDX highlights a significant presence of particles filling the wood pores. By focusing the electron beam onto these particles, intense Si-Ka emissions are revealed, therefore enabling their identification as Si-based materials. These SEM-EDX inferences are supported by the detection of Reststrahlen bands - attributed to the antisymmetric Si-O stretching vibrations - in the region from 1100 to $1000 \mathrm{~cm}^{-1}$ of the pseudo-absorbance spectra obtained by the non-invasive FTIR approach (Figure 3, c,d). Similarly to the Storioni's instruments, also layer B in the sample from the Toscano violin shows some Fe-rich grains under the SEM-EDX, recognized as iron-based pigments. 


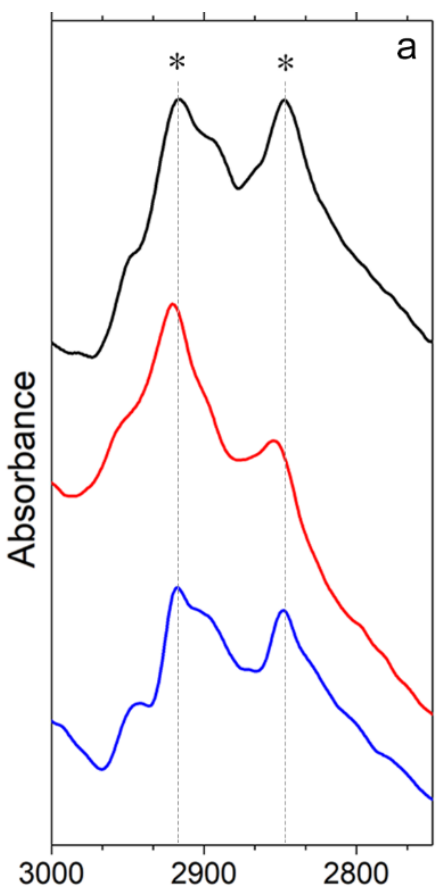

Wavenumber $\left(\mathrm{cm}^{-1}\right)$
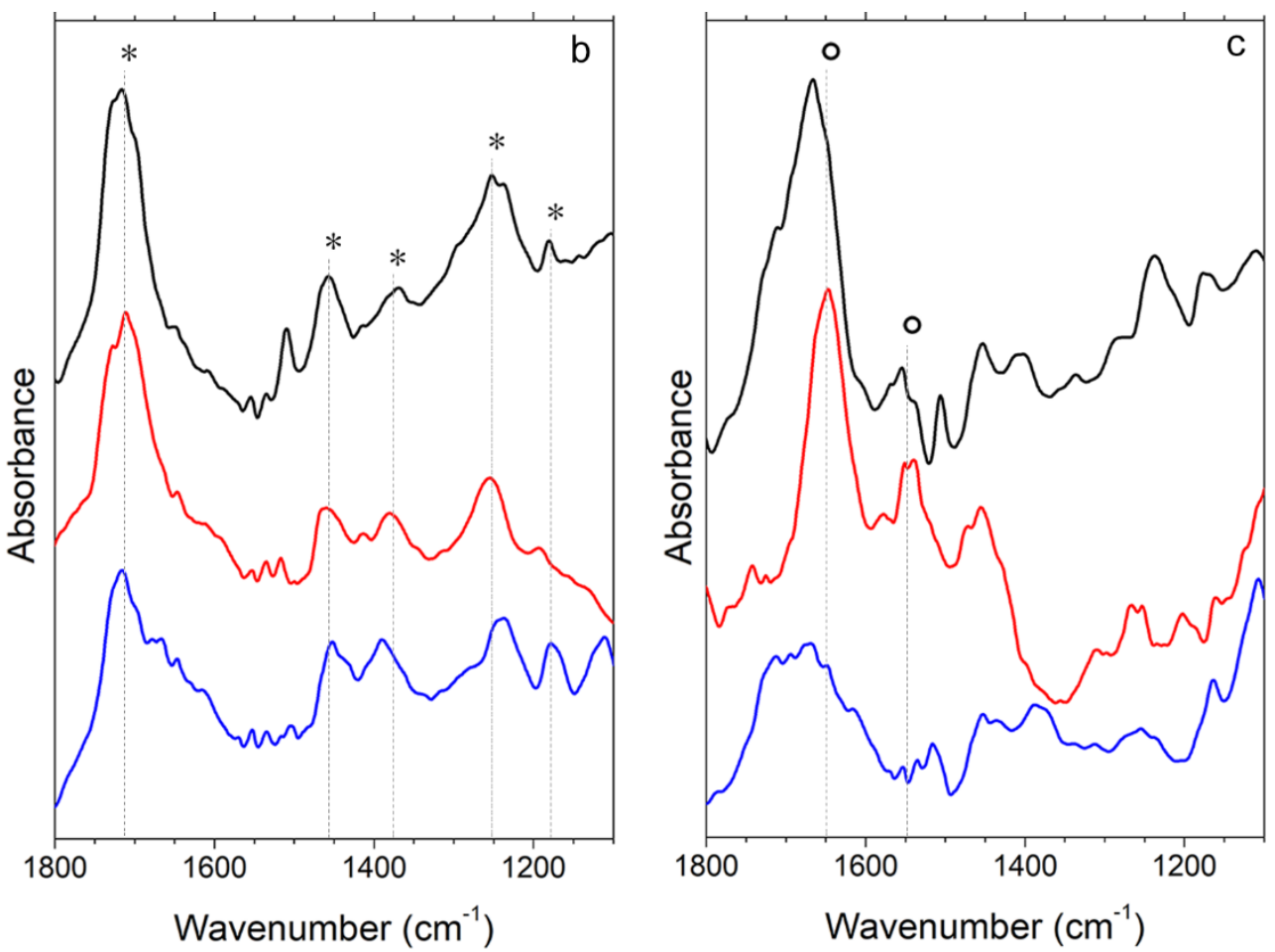

Figure 2. Reflection SR-FTIR KKT spectra collected in correspondence of the varnish layers $(a, b)$ and the ground coats (c) on the samples LS_1790 (black), LS_1793a and LS_1793b (red) and AS_1690 (blue). Spectra are shown in the ranges between $3000-2750 \mathrm{~cm}^{-1}$ (a), $1800-1100 \mathrm{~cm}^{-1}$ (b), and 1800 $1100 \mathrm{~cm}^{-1}$ (c). As for pseudo-absorbance spectra, see Figure SM2 in the Supporting Material.
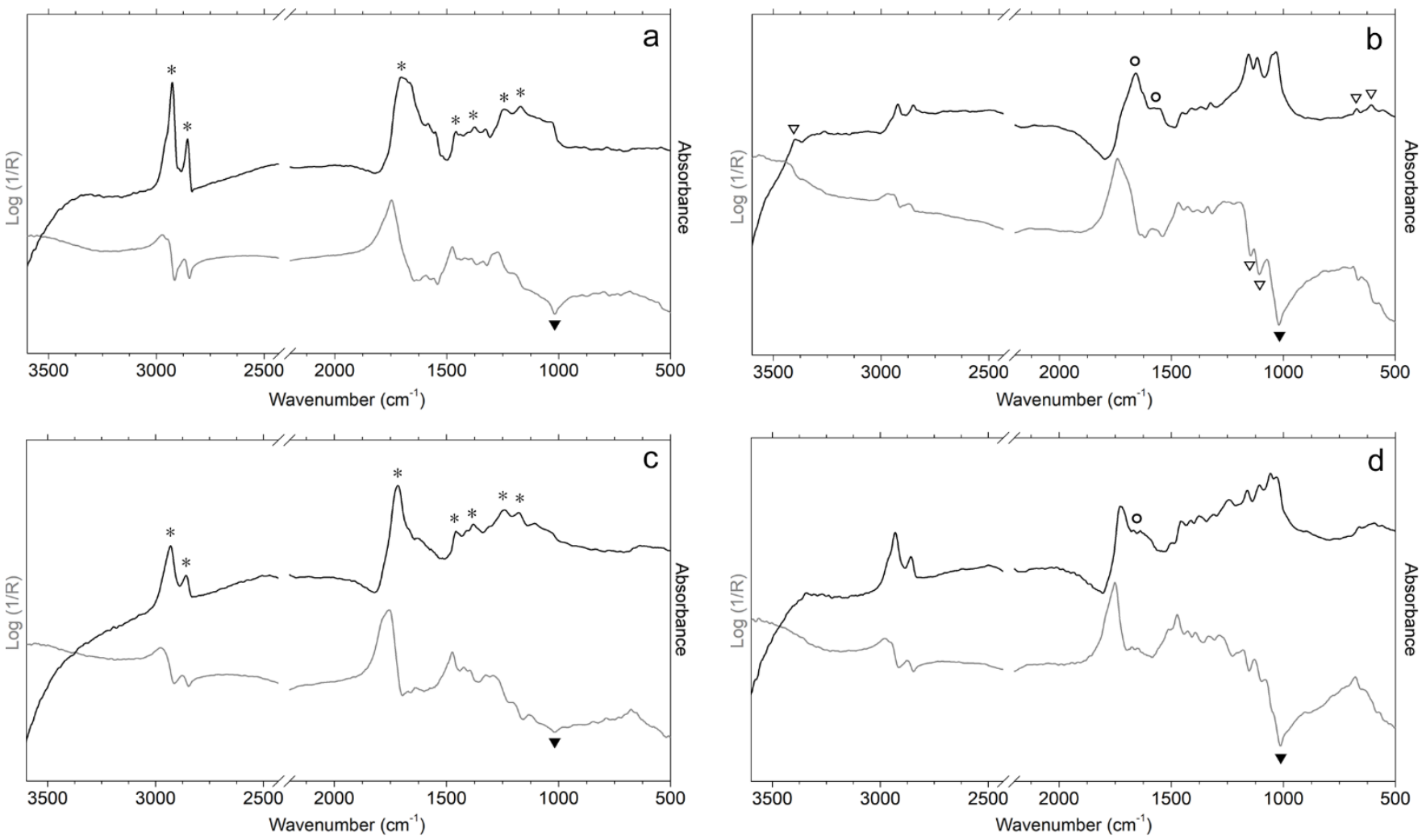

Figure 3. Reflection FTIR spectra in pseudo-absorbance (grey) and after KKT (black) acquired by the portable spectrometer on the best conserved (a) and most worn (b) varnish areas of the Bracco small violin, and on the best conserved (c) and most worn (d) varnish areas of the Toscano violin. The marker bands of each identified material are highlighted: varnish (asterisks), proteinaceous material (circles), silicates (black triangles), sulphates (white triangles). 

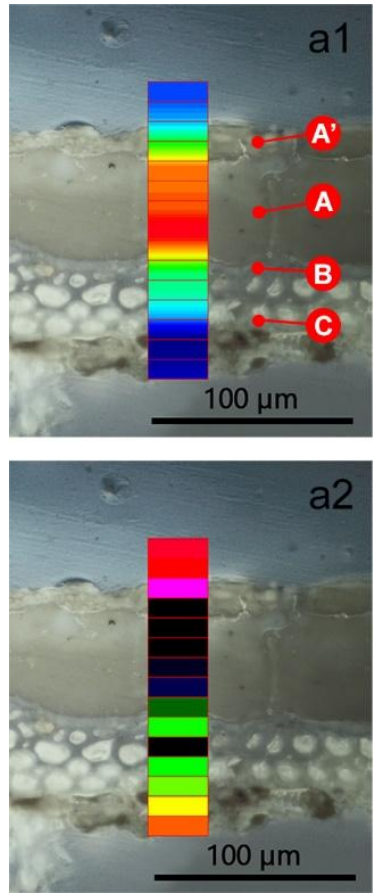
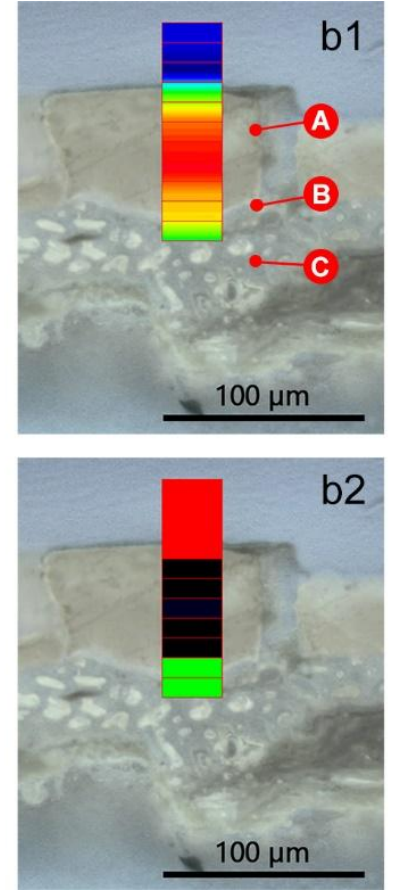
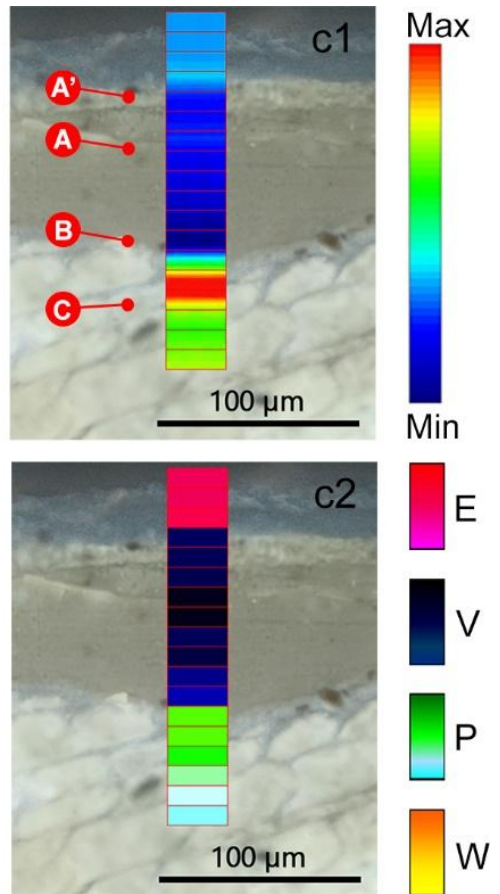

Figure 4. Univariate colour-scale maps (a1-c1), and multivariate scores maps (a2-c2) of samples LS_1790 (a1-a2), LS_1793a (b1-b2), and LS_1793b (c1-c2). The colour-scale for the univariate maps refers to the intensity of the band of the varnish at $1710 \mathrm{~cm}^{-1}(\mathrm{a} 1, \mathrm{~b} 1)$, and of the proteinaceous material

at $1650 \mathrm{~cm}^{-1}(\mathrm{c} 1)$. The resulting colours in the scores maps are related to the epoxy resin $(\mathrm{E})$, the varnish $(\mathrm{V})$, the proteinaceous preparation $(\mathrm{P})$, and the wood substrate $(\mathrm{W})$.

Chemical mapping was performed on sample LS_1790 (Figure 1, a) by considering the whole thickness of the cross-section (Figure 4, a1). As for the map obtained by the integration of the carbonyl bond stretching band centered at $1710 \mathrm{~cm}^{-1}$, the highest intensity of the signal is observed in correspondence to layer A, perfectly matching the sample stratigraphy observed by OM. Lower intensities (green areas) are identified in correspondence to the external varnish layer A', which appears with a different morphology if compared to the underlying varnish portion. Finally, the highest intensities related to signals of the proteinaceous material are highlighted in correspondence of layer $\mathrm{B}$, which has been identified as the ground coat (Figure SM3a).

Samples LS_1793a and LS_1793b (Figure 1, b,c) show similar results (Figure 4, b1,c1). Also in these cases, the maximum value for the band at $1710 \mathrm{~cm}^{-1}$ is observed in the area corresponding to the varnish layer A (Figure 4, b1) and the proteinaceous material is mainly assigned to the preparation layer B, but it also extended up to the lower portion of the varnish layer A (Figure SM3b). It is worth reporting that, as already shown in [56], some signals of proteinaceous material were also found through a non-invasive approach in well-preserved areas of the Bracco small violin, thus suggesting the presence of restoration materials in the most external layer of the coating system.

A similar picture emerges by considering the multivariate scores maps (Figure 4, a2-c2). In samples from the violins by Storioni, the rows related to layer A show colours ranging from black to dark blue, and those related to layer $B$ show colours from green to light blue. An orange area, attributed to the wood, is assigned only in the LS_1790. The interpretation of the score values, yielding different colours in the multivariate maps, is obtained by considering together scores and loadings plots (Figure 5), in order to identify spectral bands that mainly characterise each colour range. Figure 5a shows the scores plot of PC1 vs PC2 accounting for $58 \%$ of total variance. It is possible to notice that the objects cluster according to the materials in the finishing layers. Indeed, a group of objects in the bottom right quarter of the PC1 vs PC2 plot can be associated with epoxy resin. The objects linked to the varnish are mostly grouped in the bottom left quarter of PC1 vs PC2 plane, having negative PC1 scores. The grouping is 
associated with PC1 loadings (Figure $5 \mathrm{c}$ ) discriminating epoxy resin from other materials mainly thanks to the signals between $1700 \mathrm{~cm}^{-1}$ and $1600 \mathrm{~cm}^{-1}$, and those around $1500 \mathrm{~cm}^{-1}$. Objects corresponding to spectra of the proteinaceous material cluster in the positive quarters of PC2 and are characterised in the PC2 loadings - by a notable variation in the region between $1700 \mathrm{~cm}^{-1}$ and $1650 \mathrm{~cm}^{-1}$, in correspondence with the band attributed to amide I. Finally, by considering the third PC (accounting for $9 \%$ of the variance, Figure $5 \mathrm{~b}$ ), it is evident that a layer of LS_1790 assumes extremely negative PC3 scores and can be associated with the maple wood. Capital letters reported in Figure 4 for colour bars are therefore selected accordingly.
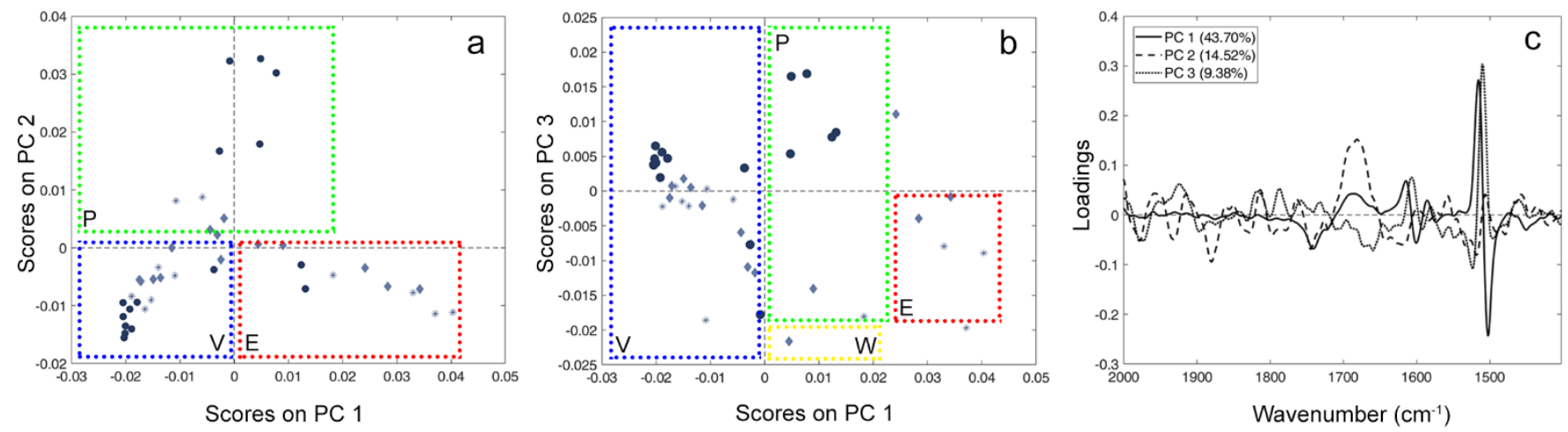

Figure 5. Scores plots from PCA on SR-FTIR spectra for samples LS_1790 (circles), LS_1793a (rhombuses), LS_1793b (asterisks): PC1 vs PC2 scores plot (a), PC1 vs PC3 scores plot (b) and loadings plot of PC1, PC2 and PC3 (c). The coloured squares in (a) and (b) include the objects indicated with $\mathrm{E}$ (embedding agent - epoxy resin, red), V (varnish, siccative oil + plant resin, blue), $\mathrm{P}$ (proteinaceous preparation, green), and W (wood substrate, yellow).
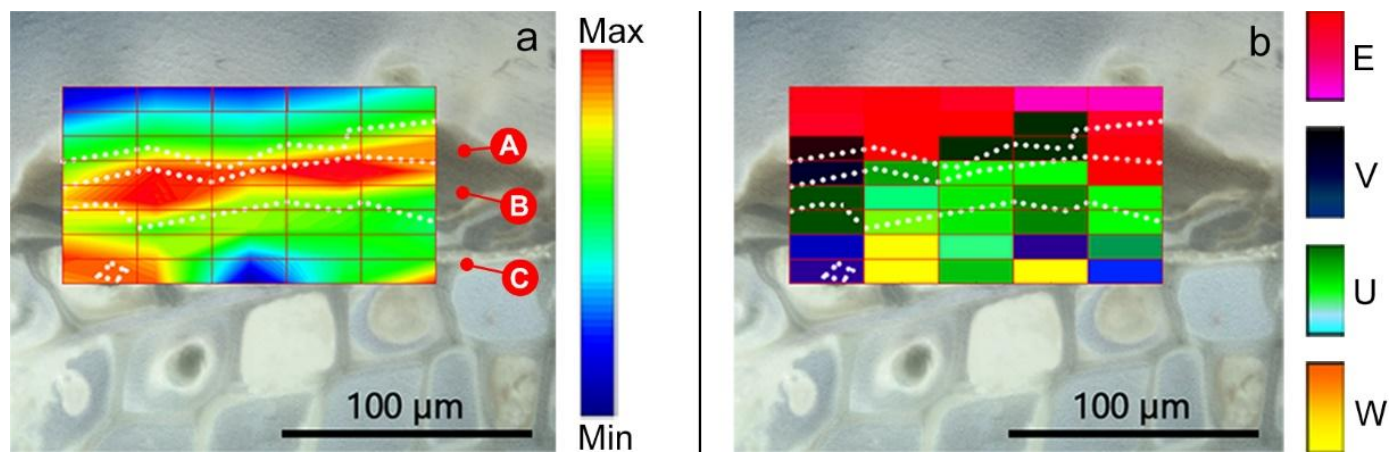

Figure 6. Univariate chemical map (a), and multivariate scores map (b) of sample AS_1690. The colourscale maps refer to the peak of the carbonyl stretching $(V C=O)$ at $1710 \mathrm{~cm}^{-1}$. The layers identified and described in the text are highlighted. The colours of the scores map are related to epoxy resin (E), varnish $(\mathrm{V})$, undefined materials $(\mathrm{U})$, and wood $(\mathrm{W})$.

Figure 7. Scores plot: PC1 vs PC2 (a) and PC1 vs PC3 (b) calculated for sample AS_1690. Objects (SR-FTIR spectra) are identified according to the position of the analytical spot in rows - from R1 to R8 of the mapping grid (reported in Figure 1). The related loadings plot is shown in Figure 5c. The coloured

squares in (a) and (b) select the objects corresponding to epoxy resin ( $E$, red), varnish ( $V$, blue), undefined material (U, green), and wood (W, yellow).

A larger area is mapped in the sample AS_1690 (Figure 6). The map reporting the intensity distribution of the $1710 \mathrm{~cm}^{-1}$ peak is shown in Figure $6 \mathrm{a}$. The red-yellow areas clearly highlight that the varnish is mainly distributed in correspondence to the two layers indicated as $A$ and $B$.

The scores map calculated for AS_1960 (Figure 6, b) partially confirms the presence of the oil-resinous varnish in layers $A$ and $B$, while the wood is correctly identified at the bottom of the stratigraphy. Even if the identification of the protein's diagnostic signals is not unambiguous here (as pointed out in Figure 2, c), dark green areas in Figure $6 \mathrm{~b}$ would suggest either wood or proteinaceous material, in accordance with previous results [27].Therefore the green portions in the multivariate map of the Stradivari sample is prudently labelled as "undefined" in Figure $6 \mathrm{~b}$.

To further investigate this topic, the loadings plot (Figure 5c) and the scores plot (Figure 7) are considered. In the scores plots, the shape of the point indicates the position of the spectrum in the rows of the mapping grid reported in Figure 6. The object distribution is due to the contribution of the original variables, whose influence is described in the loadings relative to PC1, PC2 and PC3 and reported in Figure 5c. The scores plots (Figure 7) confirm that the spectra are actually affected by signals associated with the absorption of different materials [50]. Only spectra corresponding to epoxy resin are well grouped assuming high positive PC1 and high negative PC2 values. On the contrary, the other layers are difficult to be clearly separated, therefore spectra falling in the green area in PC1 vs PC2 plot were scrutinized one by one considering both loadings and scores plots, in order to possibly gain further information. Indeed, PC2 scores more related to varnish layers are between -0.004 and +0.001 , thus being in the bottom left quarter of the PC1 vs PC2 scores plot, whereas spectra labelled as undefined assumed really high PC2 scores. However, a quite relevant group of objects are scattered thus confirming that the B-to-C interface level results from the contribution of spurious signals related to different constituents with various relative abundances, which differentiate them from those of layer $A$.

\section{Conclusions}

The combination of non- and micro-invasive reflection FTIR approaches allowed us to thoroughly investigate the materials of the finishing layers on the whole set of violins object of this work. An oilterpenic resin varnish - spread on a pre-treated wooden substrate - was identified in the Toscano violin made by Antonio Stradivari in 1690, and in the two violins made by Lorenzo Storioni in 1790 and 1793. The microscopic examination performed on the cross-sections, however, highlights some decisive differences in the stratigraphies. Stradivari varnish is composed of two thin layers of about 10-15 $\mu \mathrm{m}$ of thickness each and no evidence of a film-forming proteinaceous layer was found. This is probably due to the penetration of the ground coat into the wood pores. As for the Storioni finishing layers, one varnish layer of about $60-90 \mu \mathrm{m}$ of thickness and a proteinaceous ground coat (e.g. animal glue, casein) $10 \mu \mathrm{m}$ thick were detected. In addition, some inorganic phases - silicate, sulphate, and Febased particles - were detected on the violins by Stradivari and Storioni.

The collected results turned out to be in accordance with those obtained on other masterpieces of the Cremonese violin-making manufacture. A similar layered system was highlighted by Echard et al. [10] and by Brandmair and Greiner [63]. In their works, some well-preserved Stradivari musical instruments were investigated and comparable coatings systems were revealed: in some cases, the proteinaceous ground coat is completely penetrated in the wood pores, and the varnish is laid in two oil-resin varnish layers, as we found in the Tuscan 1690 violin. The evident difference with the stratigraphies highlighted in the Storioni violins could be explained by the progressive change of the technique that occurred in 
the late period of the Cremonese violin-making tradition, after the death of Antonio Stradivari in 1737 [63].

As for the analytical methods, both non- and micro-invasive reflection FTIR approaches were able to reveal the materials spread on the wood surfaces to finish the musical instruments under study. The micro-invasive approach allowed us to observe and characterize each layer gaining spatially resolved chemical information, in particular from the organic binders spread on the wood. These results were integrated with those obtained through the non-invasive technique, extremely useful to collect spectra from numerous analytical spots of the plate. The possibility to select areas with a gradual consumption of the varnish, in fact, enabled us to gather information directly on the varnish layers and - if exposed on the lower ground coats and from the wooden substrates. Furthermore, the inorganic phases dispersed in the binders or filled in the wood pores were identified - together with the EDX analysis thanks to the larger spectral range (up to $500 \mathrm{~cm}^{-1}$ ) of the portable equipment.

On the other hand, cross sections revealed the presence of layers with similar composition. SR beam in the micro-FTIR benchtop equipment enabled the acquisition of maps in reflection geometry avoiding any contact with the cross-section and thus preserving its whole superficial integrity. Mapping has proven its effectiveness in outlining a chemical picture of the layering. Univariate chemical maps, based on selected diagnostic absorption bands, allowed us to investigate the multi-layered structures in the samples from the musical instruments by Lorenzo Storioni and to highlight his fingerprint in the production around 1790. Despite layers being evident, boundaries are not easily defined through chemical mapping as interfaces are seldom sharp. Multivariate maps resulted in effective representations of the stratigraphy by a single false-colour image, skipping the need of diagnostic band selection. Even though the scores map are a really fast and simple method to visualise different features of the layers, this approach only recognised the predominant signals in the spectra; consequently, it is important to stress that the multivariate attribution can be influenced by the presence of complex spectra with multiple signals arising from different materials.

The investigation by reflection FTIR on cross-sectioned samples is a challenging task when such brittle and complex layered systems are considered, so the intensity of the analytical SR beam played the major role in obtaining informative FTIR spectra and the reflection geometry allowed us to fully preserve the integrity of samples. An open issue for SR-FTIR investigation reported in this work is that the chemical mapping of inorganic fillers was not successful. Further analyses aimed at characterizing these particles at a nano-scale level are ongoing.

\section{Acknowledgments}

The authors would like to thank the Fondazione Arvedi-Buschini, the Fondazione Bracco, the Fondazione Museo del Violino, the International School of Violin Making of Cremona, and the Accademia of Santa Cecilia. A special acknowledgement to Andrea Zanrè and Elisa Scrollavezza. The authors also acknowledge the CERIC-ERIC Consortium for access to experimental facilities and financial support. The activity of M. Gulmini was supported by the University of Torino "ricerca locale".

\section{References}

[1] G. Festa, S.L. Lämmlein, R. Senesi, J. Price, C. Chiesa, C. Scatigno, et al., Effect of coating systems as a barrier to humidity for lutherie woods studied by neutron radiography, Journal of Cultural Heritage. (2019). doi:10.1016/j.culher.2019.11.004.

[2] S.L. Lämmlein, D. Mannes, B.V. Damme, F.W.M.R. Schwarze, I. Burgert, The influence of multilayered varnishes on moisture protection and vibrational properties of violin wood, Scientific Reports. 9 (2019). doi:10.1038/s41598-019-54991-5.

[3] S.L. Lämmlein, B.V. Damme, D. Mannes, F.W.M.R. Schwarze, I. Burgert, Violin varnish induced changes in the vibro-mechanical properties of spruce and maple wood, Holzforschung. (2020). 
doi:10.1515/hf-2019-0182.

[4] F. Setragno, M. Zanoni, F. Antonacci, A. Sarti, M. Malagodi, T. Rovetta, C. Invernizzi, FeatureBased Analysis of the Impact of Ground Coat and Varnish on Violin Tone Qualities, Acta Acustica United with Acustica. 103 (2017) 80-93. doi:10.3813/aaa.919035.

[5] F. Caruso, S. Orecchio, M.G. Cicero, C.D. Stefano, Gas chromatography-mass spectrometry characterization of the varnish and glue of an ancient 18th century double bass, Journal of Chromatography A. 1147 (2007) 206-212. doi:10.1016/j.chroma.2007.02.048.

[6] S. Tirat, I. Degano, J.P. Echard, A. Lattuati-Derieux, A. Lluveras-Tenorio, A. Marie, S. Serfaty, J.Y. Le Huérou, Historical linseed oil/colophony varnishes formulations: Study of their molecular composition with micro-chemical chromatographic techniques, Microchemical Journal. 126 (2016) 200-213. doi:10.1016/j.microc.2015.11.045.

[7] C. Invernizzi, A. Daveri, T. Rovetta, M. Vagnini, M. Licchelli, F. Cacciatori, M. Malagodi, A multianalytical non-invasive approach to violin materials: The case of Antonio Stradivari "Hellier" (1679), Microchemical Journal. 124 (2016) 743-750. doi:10.1016/j.microc.2015.10.016.

[8] G. Fiocco, T. Rovetta, C. Invernizzi, M. Albano, M. Malagodi, M. Licchelli, A. Re, A. Lo Giudice, G.N. Lanzafame, F. Zanini, M. Iwanicka, P. Targowski, M. Gulmini, A Micro-Tomographic Insight into the Coating Systems of Historical Bowed String Instruments, Coatings. 9 (2019) 81. doi:10.3390/coatings 9020081.

[9] T. Rovetta, C. Invernizzi, G. Fiocco, M. Albano, M. Licchelli, M. Gulmini, G. Alf, D. Fabbri, A.G. Rombolà, M. Malagodi, The case of Antonio Stradivari 1718 ex-San Lorenzo violin: History, restorations and conservation perspectives, Journal of Archaeological Science: Reports. 23 (2019) 443-450. doi:10.1016/j.jasrep.2018.11.010.

[10] J.P. Echard, L. Bertrand, A. Von Bohlen, A.-S. Le Hô, C. Paris, L. Bellot-Gurlet, B. Soulier, A. Lattuati-Derieux, S. Thao, L. Robinet, B. Lavédrine, S. Vaiedelich, The Nature of the Extraordinary Finish of Stradivari's Instruments, Angewandte Chemie International Edition. 49 (2009) 197-201. doi:10.1002/anie.200905131.

[11] F. Caruso, D.F.C. Martino, S. Saverwyns, M.V. Bos, L. Burgio, C. Di Stefano, G. Peschke, E. Caponetti, Micro-analytical identification of the components of varnishes from South Italian historical musical instruments by PLM, ESEM-EDX, microFTIR, GC-MS, and Py-GC-MS, Microchemical Journal. 116 (2014) 31-40. doi:10.1016/j.microc.2014.04.002.

[12] G. Fiocco, T. Rovetta, M. Gulmini, A. Piccirillo, C. Canevari, M. Licchelli, et al., Approaches for Detecting Madder Lake in Multi-Layered Coating Systems of Historical Bowed String Instruments, Coatings. 8 (2018) 171. doi:10.3390/coatings8050171.

[13] B.H. Tai, Stradivari's Varnish: A review of scientific findings - Part II. Journal of the Violin Society of America. 22 (2009) 1-31.

[14] B.H. Tai, Stradivari's Varnish: A review of scientific findings - Part I. Journal of the Violin Society of America. 21 (2007) 119-144.

[15] F. Poggialini, G. Fiocco, B. Campanella, S. Legnaioli, V. Palleschi, M. Iwanicka, et al., Stratigraphic analysis of historical wooden samples from ancient bowed string instruments by laser induced breakdown spectroscopy, Journal of Cultural Heritage. (2020). doi:10.1016/j.culher.2020.01.011.

[16] J.P. Echard, B. Lavédrine, Review on the characterisation of ancient stringed musical instruments varnishes and implementation of an analytical strategy, Journal of Cultural Heritage. 9 (2008) 420429. doi:10.1016/j.culher.2008.03.005.

[17] C. Daher, C. Paris, A.S. Le Hô, L. Bellot-Gurlet, J.P. Échard, A joint use of Raman and infrared spectroscopies for the identification of natural organic media used in ancient varnishes, Journal of Raman Spectroscopy. 41 (2010) 1494-1499. doi:10.1002/jrs.2693.

[18] G. Fiocco, T. Rovetta, M. Malagodi, M. Licchelli, M. Gulmini, G. Lanzafame, F. Zanini, A. Lo Giudice, A. Re, Synchrotron radiation micro-computed tomography for the investigation of finishing treatments in historical bowed string instruments: Issues and perspectives, The European Physical 
Journal Plus. 133 (2018). doi:10.1140/epjp/i2018-12366-5.

[19] C. Invernizzi, A. Daveri, M. Vagnini, M. Malagodi, Non-invasive identification of organic materials in historical stringed musical instruments by reflection infrared spectroscopy: a methodological approach, Analytical and Bioanalytical Chemistry. 409 (2017) 3281-3288. doi:10.1007/s00216017-0296-8.

[20] J.P. Echard, In situ multi-element analyses by energy-dispersive X-ray fluorescence on varnishes of historical violins, Spectrochimica Acta Part B: Atomic Spectroscopy. 59 (2004) 1663-1667. doi:10.1016/j.sab.2004.05.026.

[21] G. Fichera, T. Rovetta, G. Fiocco, G. Alberti, C. Invernizzi, M. Licchelli, M. Malagodi, Elemental analysis as statistical preliminary study of historical musical instruments, Microchemical Journal. 137 (2018) 309-317. doi:10.1016/j.microc.2017.11.004.

[22] T. Rovetta, C. Invernizzi, M. Licchelli, F. Cacciatori, M. Malagodi, The elemental composition of Stradivari's musical instruments: new results through non-invasive EDXRF analysis, X-Ray Spectrometry. 47 (2018) 159-170. doi: 10.1002/xrs.2825.

[23] J.P. Echard, C. Benoit, J. Peris-Vicente, V. Malecki, J. Gimeno-Adelantado, S. Vaiedelich, Gas chromatography/mass spectrometry characterization of historical varnishes of ancient Italian lutes and violin, Analytica Chimica Acta. 584 (2007) 172-180. doi:10.1016/j.aca.2006.10.048.

[24] A. Von Bohlen, S. Röhrs, J. Salomon, Spatially resolved element analysis of historical violin varnishes by use of $\mu$ PIXE, Analytical and Bioanalytical Chemistry. 387 (2006) 781-790. doi:10.1007/s00216-006-0777-7

[25] G. Fiocco, T. Rovetta, M. Gulmini, A. Piccirillo, M. Licchelli, M. Malagodi, Spectroscopic Analysis to Characterize Finishing Treatments of Ancient Bowed String Instruments, Applied Spectroscopy. 71 (2017) 2477-2487. doi:10.1177/0003702817715622.

[26] C. Miliani, F. Rosi, A. Daveri, B.G. Brunetti, Reflection infrared spectroscopy for the non-invasive in situ study of artists' pigments, Appl. Phys. A 106 (2011) 295-307. doi:10.1007/s00339-0116708-2.

[27] C. Invernizzi, G.V. Fichera, M. Licchelli, M. Malagodi, A non-invasive stratigraphic study by reflection FT-IR spectroscopy and UV-induced fluorescence technique: The case of historical violins, Microchemical Journal. 138 (2018) 273-281. doi:10.1016/j.microc.2018.01.021.

[28] M. Cotte, P. Dumas, Y. Taniguchi, E. Checroun, P. Walter, J. Susini, Recent applications and current trends in Cultural Heritage Science using synchrotron-based Fourier transform infrared micro-spectroscopy, Comptes Rendus Physique. 10 (2009) 590-600. doi:10.1016/j.crhy.2009.03.016.

[29] S. Prati, G. Sciutto, I. Bonacini, R. Mazzeo, New Frontiers in Application of FTIR Microscopy for Characterization of Cultural Heritage Materials, Topics in Current Chemistry. 374 (2016). doi:10.1007/s41061-016-0025-3.

[30] J.V.D. Weerd, R.M.A. Heeren, J.J. Boon, Preparation Methods and Accessories for the Infrared Spectroscopic Analysis of Multi-Layer Paint Films, Studies in Conservation. 49 (2004) 193. doi:10.2307/25487692.

[31] S. Prati, G. Sciutto, E. Catelli, A. Ashashina, R. Mazzeo, Development of innovative embedding procedures for the analyses of paint cross sections in ATR FITR microscopy, Analytical and Bioanalytical Chemistry. 405 (2012) 895-905. doi:10.1007/s00216-012-6435-3.

[32] E. Pouyet, A. Lluveras-Tenorio, A. Nevin, D. Saviello, F. Sette, M. Cotte, Preparation of thinsections of painting fragments: Classical and innovative strategies, Analytica Chimica Acta. 822 (2014) 51-59. doi:10.1016/j.aca.2014.03.025.

[33] K. Jalovec, Italian violin makers, Crown, 1957.

[34] N. Salvadó, S. Butí, M.J. Tobin, E. Pantos, A.J. Prag, T. Pradell, Advantages of the Use of SR-FTIR Microspectroscopy: Applications to Cultural Heritage, Analytical Chemistry. 77 (2005) 34443451. doi:10.1021/ac050126k.

[35] L. Bertrand, L. Robinet, S.X. Cohen, C. Sandt, A.-S.L. Hô, B. Soulier, A. Lattuati-Derieux, J.P. 
Echard, Identification of the finishing technique of an early eighteenth century musical instrument using FTIR spectromicroscopy, Analytical and Bioanalytical Chemistry. 399 (2010) 3025-3032. doi:10.1007/s00216-010-4288-1.

[36] J.P. Echard, M. Cotte, E. Dooryhee, L. Bertrand, Insights into the varnishes of historical musical instruments using synchrotron micro-analytical methods, Applied Physics A. 92 (2008) 77-81. doi:10.1007/s00339-008-4449-7.

[37] V. Crupi, M.F.L. Russa, V. Venuti, S. Ruffolo, M. Ricca, G. Paladini, et al., A combined SR-based Raman and InfraRed investigation of pigmenting matter used in wall paintings: The San Gennaro and San Gaudioso Catacombs (Naples, Italy) case, The European Physical Journal Plus. 133 (2018). doi:10.1140/epjp/i2018-12231-7.

[38] K. Sano, S. Arrighi, C. Stani, D. Aureli, F. Boschin, I. Fiore, et al., The earliest evidence for mechanically delivered projectile weapons in Europe, Nature Ecology \& Evolution. 3 (2019) 14091414. doi:10.1038/s41559-019-0990-3.

[39] S. Sotiropoulou, Z.E. Papliaka, L. Vaccari, Micro FTIR imaging for the investigation of deteriorated organic binders in wall painting stratigraphies of different techniques and periods, Microchemical Journal. 124 (2016) 559-567. doi:10.1016/j.microc.2015.10.002.

[40] G. Sciutto, P. Oliveri, S. Prati, M. Quaranta, S. Bersani, R. Mazzeo, An advanced multivariate approach for processing $X$-ray fluorescence spectral and hyperspectral data from non-invasive in situ analyses on painted surfaces, Analytica Chimica Acta. 752 (2012) 30-38. doi:10.1016/j.aca.2012.09.035.

[41] F. Rosi, A. Federici, B.G. Brunetti, A. Sgamellotti, S. Clementi, C. Miliani, Multivariate chemical mapping of pigments and binders in easel painting cross-sections by micro IR reflection spectroscopy, Analytical and Bioanalytical Chemistry. 399 (2010) 3133-3145. doi:10.1007/s00216010-4239-x.

[42] G. Sciutto, P. Oliveri, S. Prati, M. Quaranta, S. Lanteri, R. Mazzeo, Analysis of paint crosssections: a combined multivariate approach for the interpretation of $\mu$ ATR-FTIR hyperspectral data arrays, Analytical and Bioanalytical Chemistry. 405 (2012) 625-633. doi:10.1007/s00216-0115680-1.

[43] G. Sciutto, P. Oliveri, S. Prati, E. Catelli, I. Bonacini, R. Mazzeo, A Multivariate Methodological Workflow for the Analysis of FTIR Chemical Mapping Applied on Historic Paint Stratigraphies, International Journal of Analytical Chemistry. 2017 (2017) 1-12. doi:10.1155/2017/4938145.

[44] P. Oliveri, M. Forina, Data Analysis and Chemometrics, Chemical Analysis of Food: Techniques and Applications. (2012) 25-57. doi:10.1016/b978-0-12-384862-8.00002-9.

[45] P. Dondi, L. Lombardi, C. Invernizzi, T. Rovetta, M. Malagodi, M. Licchelli, Automatic Analysis of UV-Induced Fluorescence Imagery of Historical Violins, Journal on Computing and Cultural Heritage. 10 (2017) 1-13. doi:10.1145/3051472.

[46] P. Dondi, L. Lombardi, M. Malagodi, M. Licchelli, Automatic identification of varnish wear on historical instruments: The case of Antonio Stradivari violins, Journal of Cultural Heritage. 22 (2016) 968-973. doi:10.1016/j.culher.2016.05.010.

[47] S. Lupi, A. Nucara, A. Perucchi, P. Calvani, M. Ortolani, L. Quaroni, M. Kiskinova, Performance of SISSI, the infrared beamline of the ELETTRA storage ring, Journal of the Optical Society of America B. 24 (2007) 959. doi:10.1364/josab.24.000959.

[48] S. Wold, K. Esbensen, P. Geladi, Principal component analysis, Chemometrics and Intelligent Laboratory Systems. 2 (1987) 37-52. doi:10.1016/0169-7439(87)80084-9.

[49] R. Bro, A.K. Smilde, Principal component analysis, Analytical Methods. 6 (2014) 2812-2831. doi:10.1039/c3ay41907j.

[50] S. Grassi, G. Fiocco, C. Invernizzi, T. Rovetta, M. Albano, P. Davit, M. Gulmini, C. Stani, L. Vaccari, M. Licchelli, M. Malagodi, Managing complex Synchrotron radiation FTIR micro-spectra from historic bowed musical instruments by chemometrics, 2019 IMEKO TC4 International Conference on Metrology for Archaeology and Cultural Heritage, MetroArchaeo 2019. 
[51] M.G. González, J.C. Cabanelas, J. Baselga, Applications of FTIR on Epoxy Resins - Identification, Monitoring the Curing Process, Phase Separation and Water Uptake, Infrared Spectroscopy Materials Science, Engineering and Technology. (2012). doi:10.5772/36323.

[52] R.E. Smith, F.N. Larsen, C.L. Long, Epoxy resin cure. II. FTIR analysis, Journal of Applied Polymer Science. 29 (1984) 3713-3726. doi:10.1002/app.1984.070291207.

[53] H. Panda, Epoxy Resins Technology Handbook (Manufacturing Process, Synthesis, Epoxy Resin Adhesives and Epoxy Coatings). (2016).

[54] C. Invernizzi, T. Rovetta, M. Licchelli, M. Malagodi, Mid and Near-Infrared Reflection Spectral Database of Natural Organic Materials in the Cultural Heritage Field, International Journal of Analytical Chemistry. 2018 (2018) 1-16. doi:10.1155/2018/7823248.

[55] K. Belbachir, R. Noreen, G. Gouspillou, C. Petibois, Collagen types analysis and differentiation by FTIR spectroscopy, Analytical and Bioanalytical Chemistry. 395 (2009) 829-837. doi:10.1007/s00216-009-3019-y.

[56] C. Invernizzi, G. Fiocco, M. Iwanicka, M. Kowalska, P. Targowski, B. Blümich, et al., Non-invasive mobile technology to study the stratigraphy of ancient Cremonese violins: OCT, NMR-MOUSE, XRF and reflection FT-IR spectroscopy, Microchemical Journal. 155 (2020) 104754. doi:10.1016/j.microc.2020.104754.

[57] E. Knittle, W. Phillips, Q. Williams, An infrared and Raman spectroscopic study of gypsum at high pressures, Physics and Chemistry of Minerals. 28 (2001) 630-640. doi:10.1007/s002690100187.

[58] M.R. Derrick, D. Stulik, J.M. Landry, Infrared spectroscopy in conservation science, Getty Conservation Institute, 1999.

[59] J. Nagyvary, R.N. Guillemette, C.H. Spiegelman, Mineral Preservatives in the Wood of Stradivari and Guarneri, PLoS ONE. 4 (2009). doi:10.1371/journal.pone.0004245.

[60] CY., Barlow,J. Woodhouse, Of old wood and varnish: peering into the can of worms, Journal of the Catgut Acoustical Society, Series II. 1 (1989) 2-9.

[61] N. Eastaugh, Pigment compendium: a dictionary and optical microscopy of historical pigments, Routledge, 2013.

[62] N. Bevilacqua, L. Borgioli, I. Adrover Gracia, I pigmenti nell'arte: dalla preistoria alla rivoluzione industriale, II prato, 2010.

[63] B. Brandmair, S.-P. Greiner, Stradivari Varnish: scientific analysis of his finishing technique on selected instruments, 2010. 
Click here to download high resolution image
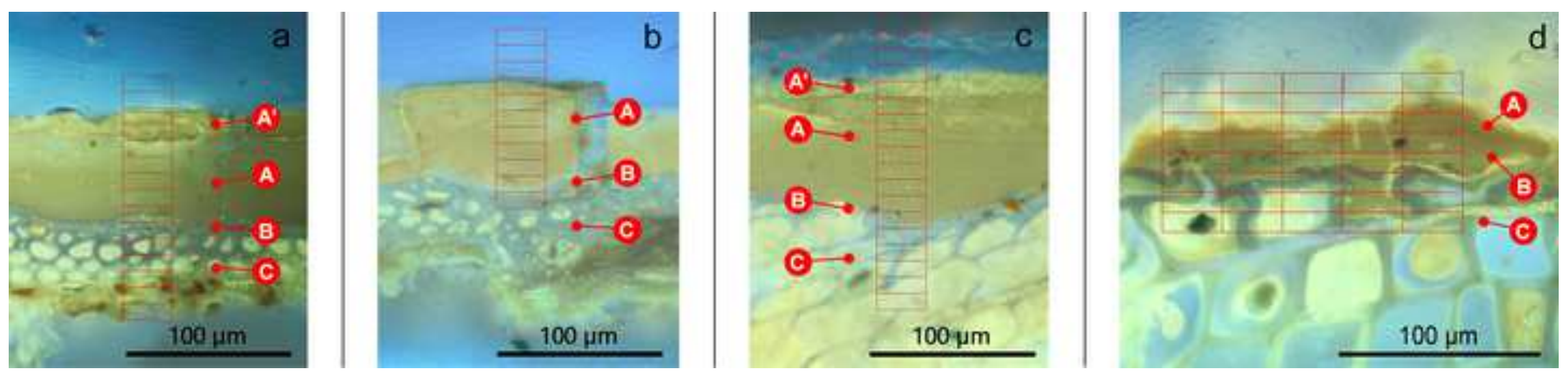

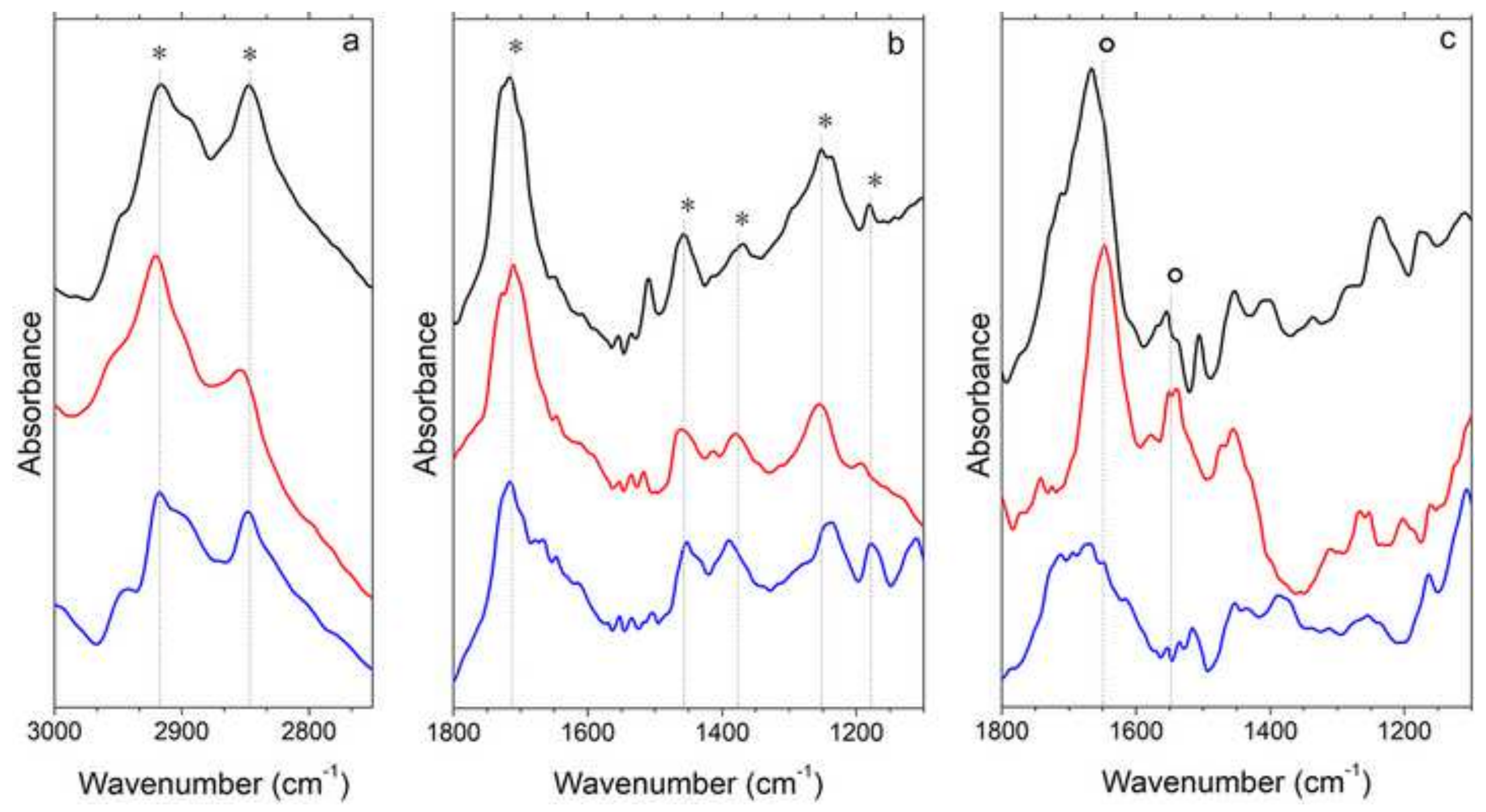

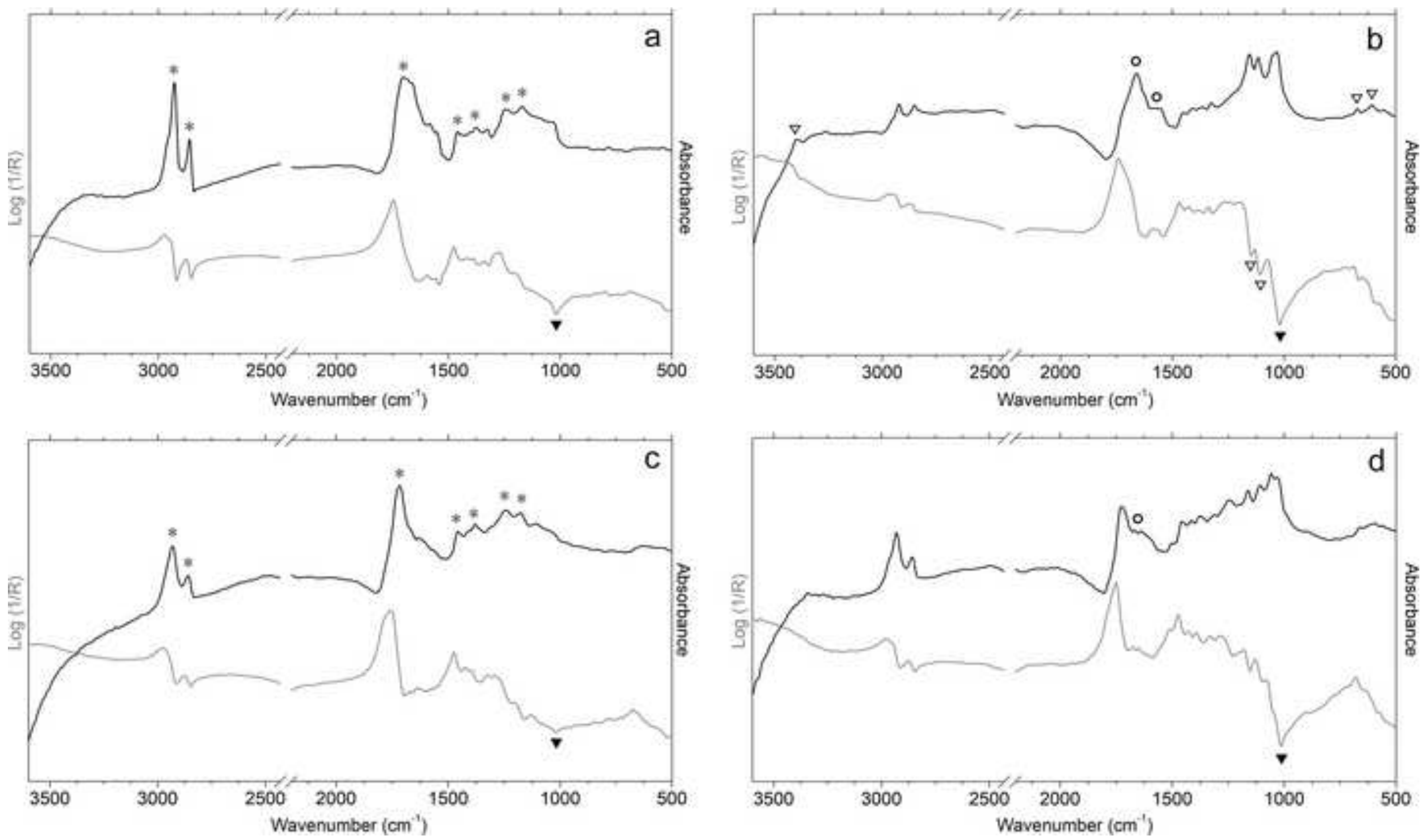
00 

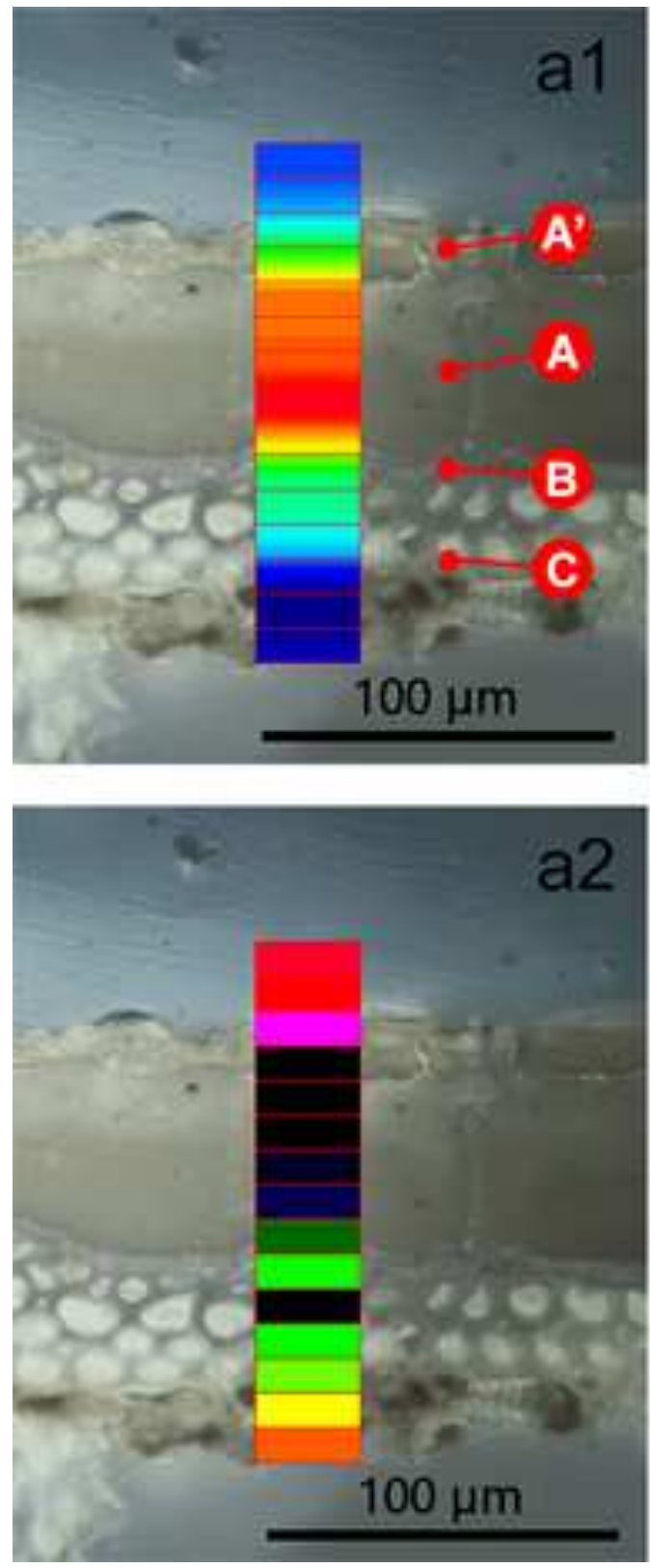
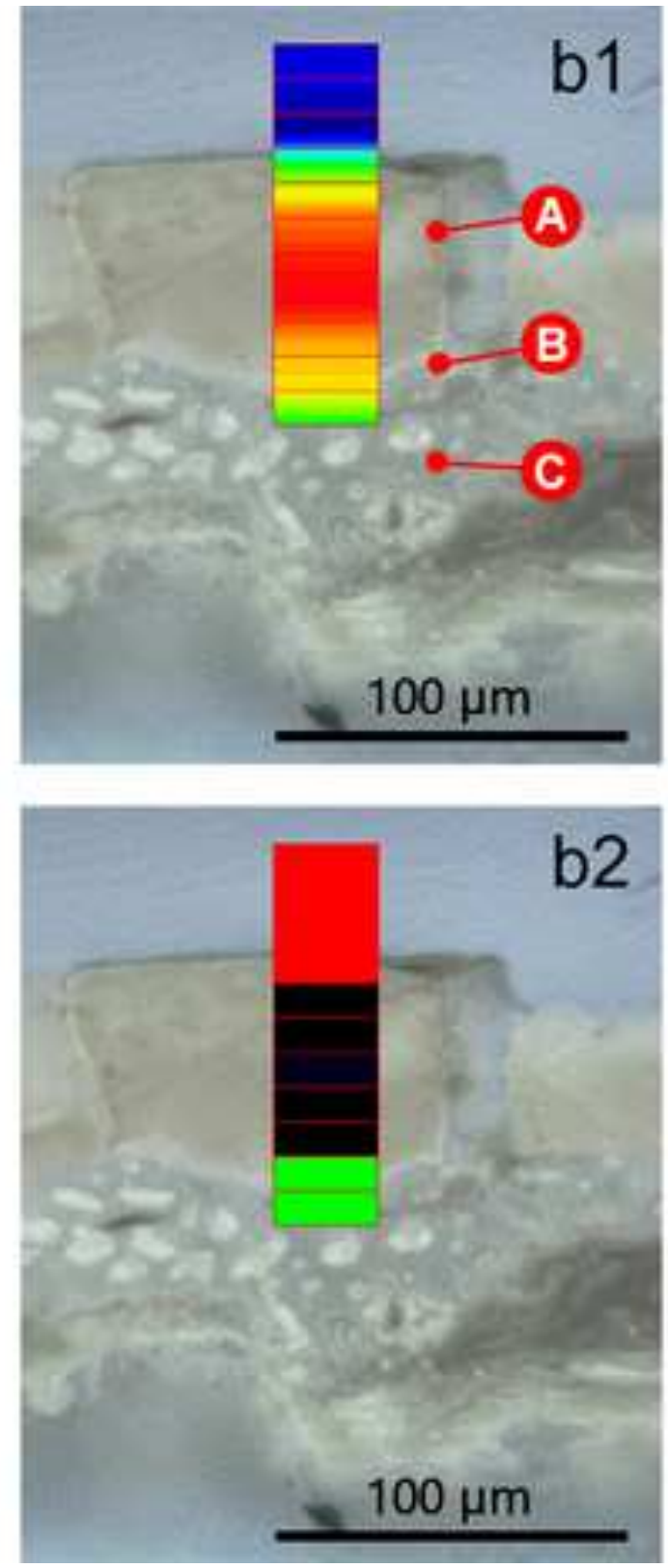

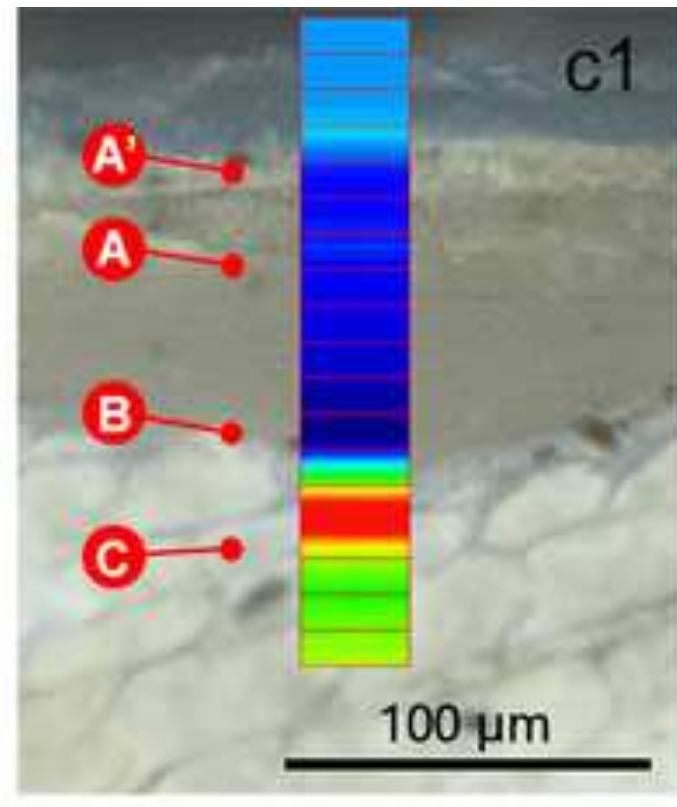

Max
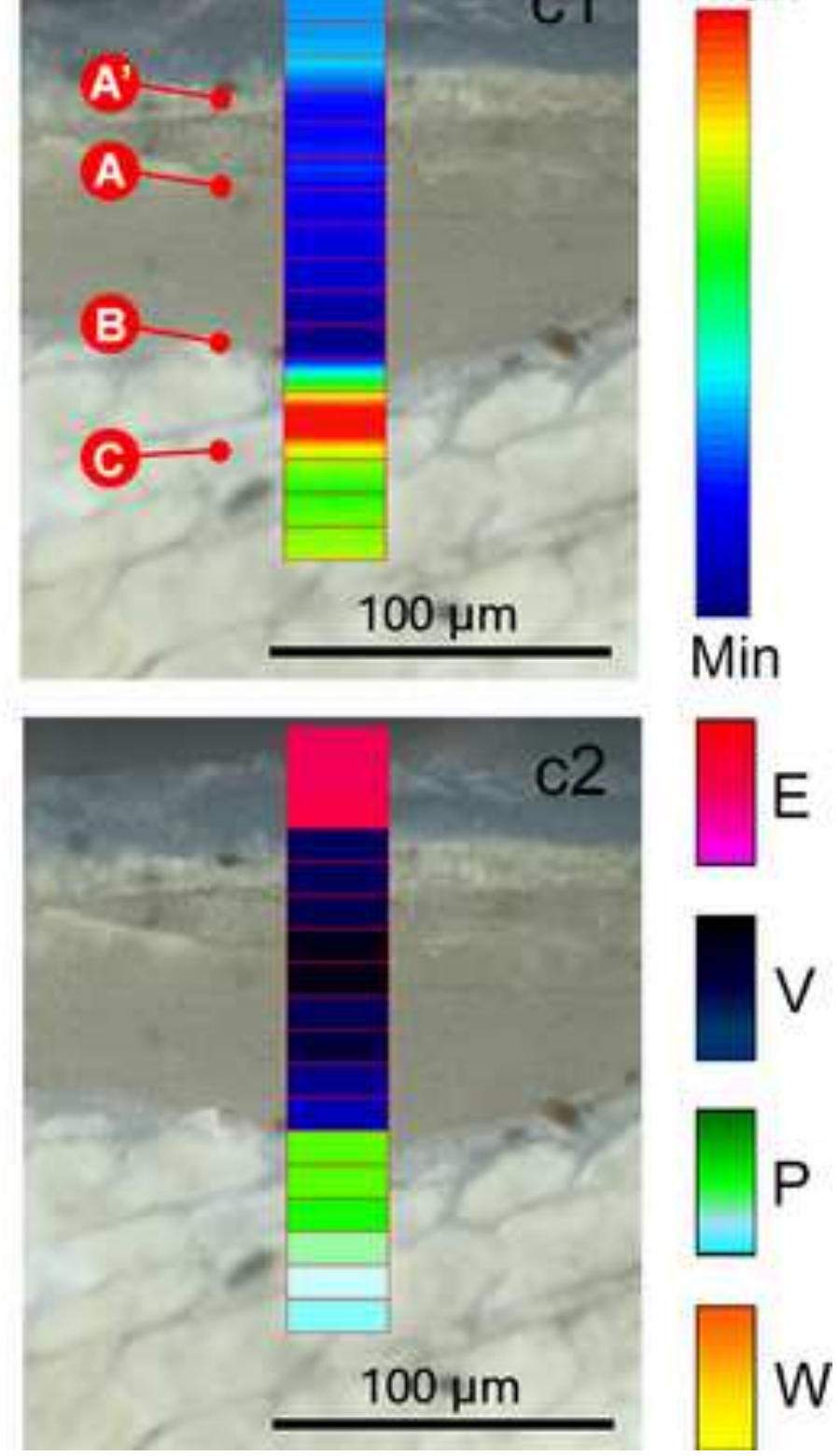

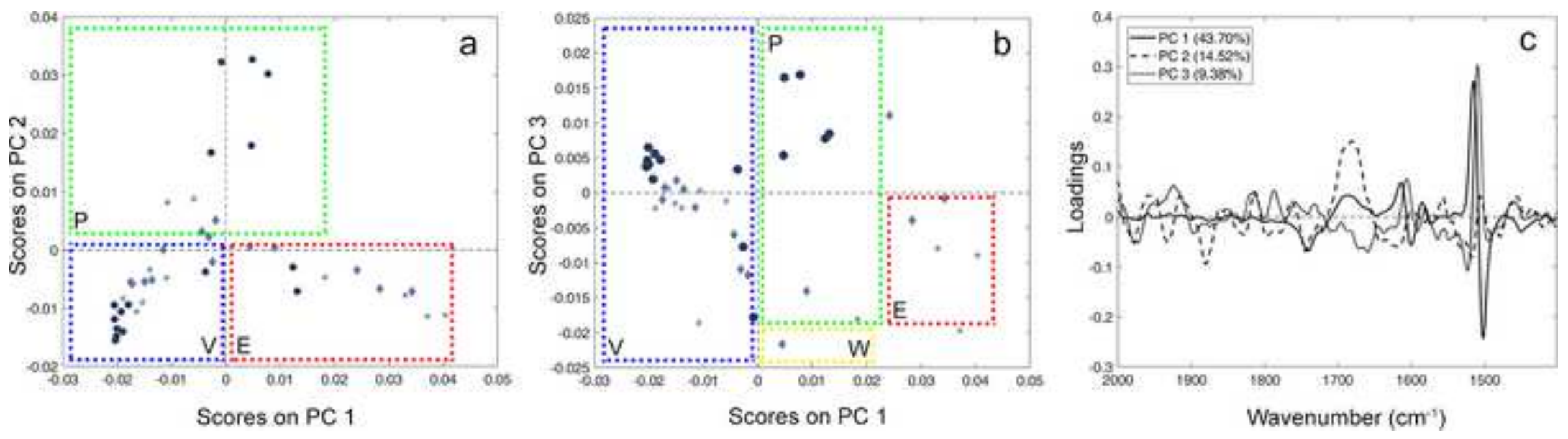


Table 1. List of the violin makers, violins and related cross-sectioned samples.

\begin{tabular}{cccccc}
\hline Violin maker & $\begin{array}{c}\text { Instrument } \\
\text { name }\end{array}$ & $\begin{array}{c}\text { Year of } \\
\text { construction }\end{array}$ & Type & Part & Sample code \\
\hline \multirow{2}{*}{ L. Storioni $(1744-1816)$} & - & 1790 & Violin & Backplate & LS_1790 \\
\cline { 2 - 6 } & Bracco & 1793 & Small violin & Backplate & LS_1793a \\
\cline { 2 - 6 } & & & Frontplate & LS_1793b \\
\hline A. Stradivari $(1644-1737)$ & Toscano & 1690 & Violin & Frontplate & AS_1690 \\
\hline
\end{tabular}



Supplementary Material
Click here to download Si Supplementary Material
Click here to download Supplementary Material: Fiocco et al - Spec Acta A - SUPPLEMENTARY MATERIALS_sent.docx 
Università degli Studi di Torino

Dipartimento di Chimica

Via P. Giuria, 710125 Torino Italy

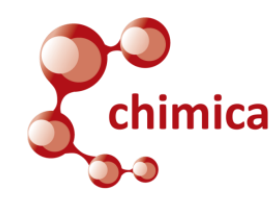

Dott.ssa PhD Monica Gulmini

phone: +390116705265

e-mail: monica.gulmini@unito.it

AMAMASA TEAM

Archeometria e Metodi Analitici per Materiali Artistici, Storici e Archeologici

Torino $-06^{\text {th }}$ April, 2020

\section{Declaration of interests}

$\bigotimes$ The authors declare that they have no known competing financial interests or personal relationships that could have appeared to influence the work reported in this paper.

$\bigotimes$ The authors declare the following financial interests/personal relationships which may be considered as potential competing interests:

The declaration is given by the corresponding author on behalf of all the co- authors of the manuscript entitled:

"Reflection FTIR spectroscopy for the study of historical bowed string instruments: invasive and non-invasive approaches"

The manuscript is submitted to Spectrochimica Acta part A - Molecular and Biomolecular Spectroscopy.

Yours sincerely,

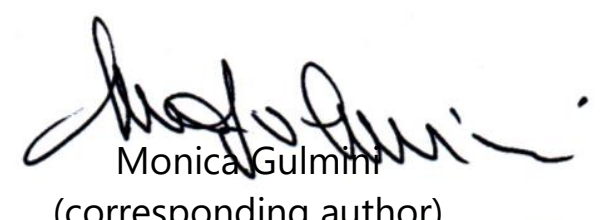

(corresponding author) 